\title{
A Protection Method Based on Feature Cosine and Differential Scheme for Microgrid
}

\author{
Lai Lei $\mathbb{D},{ }^{1,2}$ Cong Wang, ${ }^{1}$ Jie Gao $\mathbb{D},^{3}$ Jinjin Zhao, ${ }^{2}$ and Xiaowei Wang $\mathbb{C}{ }^{4,5}$ \\ ${ }^{1}$ China University of Mining \& Technology, Beijing 100083, China \\ ${ }^{2}$ Zhengzhou Electric Power College, Zhengzhou 450000, China \\ ${ }^{3}$ Shanghai University of Electric Power, Shanghai 200090, China \\ ${ }^{4}$ Xian Jiaotong University, Xi'an 710049, China \\ ${ }^{5}$ Henan Polytechnic University, Jiaozuo 454000, China \\ Correspondence should be addressed to Lai Lei; 1215894189@qq.com
}

Received 26 October 2018; Revised 25 January 2019; Accepted 19 February 2019; Published 10 March 2019

Academic Editor: Yakov Strelniker

Copyright (c) 2019 Lai Lei et al. This is an open access article distributed under the Creative Commons Attribution License, which permits unrestricted use, distribution, and reproduction in any medium, provided the original work is properly cited.

The fault current level of microgrid is different between islanded mode and grid connected mode. This situation degrades the performance of traditional overcurrent protection schemes. Hence, this paper proposes a protection method based on feature cosine and differential scheme. Firstly, feature cosine is proposed; it employs ellipse equation and minimum least squares to quantify the united behavior about voltage and current. Secondly, fault current direction and feature cosine are analyzed when fault occurs at different locations of a typical microgrid, and then the difference of feature cosine between faulty and healthy section locations is obtained. Thirdly, based on feature cosine and differential scheme, the differential direction is defined and utilized to detect faulty section location. Lastly, various time domain simulation case studies, including different microgrid operation modes, grounding resistances, faulty types, faulty section locations, and noise influence, are conducted and demonstrate that the proposed protection has high accuracy.

\section{Introduction}

Due to climate concern, technological advancements, and government incentives, microgrids are emerging as a lowmedium voltage energy network which include various types of distributed generation (DG) such as solar, wind, and geothermal $[1,2]$. Some advantages of the presence of microgrids include reduction of power delivery loss, reduced greenhouse gases, and enhancement of power reliability.

However, the emergence of microgrids involves a lot of technical challenges, e.g., voltage and frequency control, stability problems, power quality, and so on, because microgrid operation, control, and protection are typically different from those of traditional power networks [3-5]. One of the major issues in microgrid is the microgrid protection. Different reasons responsible for this are as follows: (i) power flow may become bidirectional when DGs are integrated into the microgrid; (ii) fault current levels may be limited to $2 \sim 3$ times the inverter-rated current; (iii) the microgrid may connect or disconnect DGs; (iv) the microgrid has two operation modes including islanded and grid connected modes; (v) zero and negative sequence currents cannot be neglected in normal conditions since single- and three-phase unbalanced loads are embedded into microgrids.

At present, scholars have proposed various methods to protect microgrids. Reference [6] proposes a three-stage approach to microgrid protection including offline analyses, online calculation, and real-time protection, which is based on establishing dynamic security model in microgrid. Reference [7] employs hysteresis control and maximum current RMS control to limit the fault current; it can make fault current have a percentage of fifth harmonic which is utilized to build protection strategy, but this method is only suitable for islanded microgrid. Reference [8] investigates protection issues related to LV microgrids and elaborates LV microgrid protection concepts comprehensively. Voltage and frequency relays are used as a point of common coupling relay, and directional overcurrent (DOC) relay is utilized for feeder 


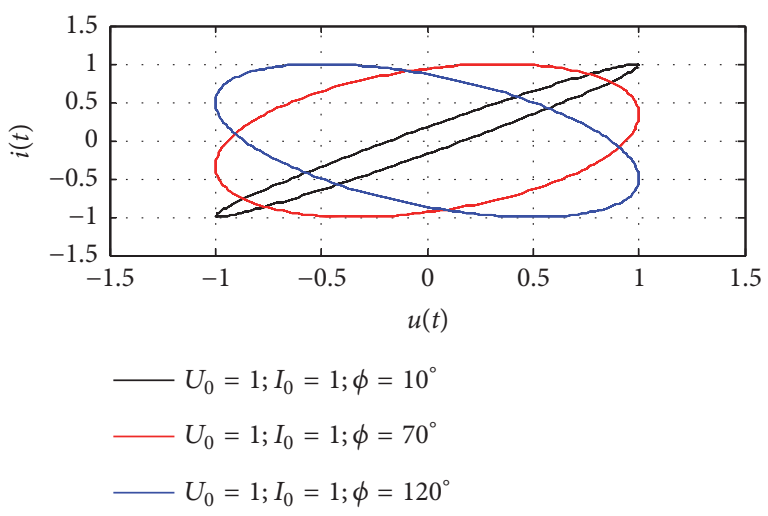

(a)

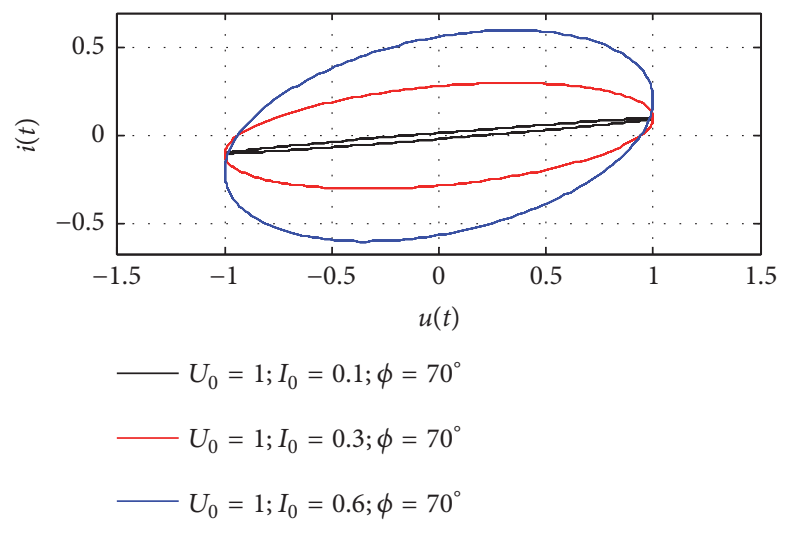

(b)

FIGURE 1: Elliptical behavior of a phase in a bus for different situations. (a) Elliptical behavior of a phase in a bus for different values of $\phi$ and (b) elliptical behavior of a phase in a bus for different values of $I_{0}$.

protection. DOC takes a long time to operate. Besides, with its operation, all of the feeder elements should be tripped. In $[9,10]$, sequence components, e.g., positive and negative sequence components, are employed to design the protection, but it can make relay coordination become more complex because of multiple settings. Reference [11] has proposed a novel fault location method based on the maximum oscillation magnitude of the transient voltage signal, but this method does not consider the three-phase microgrid. The d$\mathrm{q}$ wavelet packet transform-based digital protection has been implemented to investigate several transient disturbances occurring in different parts of the microgrid system [12]; it suffers a problem about choosing suitable wavelet basis functions. Two time-frequency-based differential schemes, which can avoid the selection of wavelet basis functions, are presented for microgrid protection; one is the HilbertHuang transform [13], and the other is the generalized Stransform [14]. In these two works, how to find effective threshold is necessary. This problem can be avoided by some statistical classifiers; for instance, $[15,16]$ have used the threephase voltage amplitude, voltage total harmonic distortions, and other 19 electrical features to build classifiers including Decision Tree and Naive Bayes, to detect fault and achieve protection; [17] has utilized combined wavelet transform and decision tree to detect and classify the fault; however, the protection strategies in $[15,16]$ are only designed for islanded microgrid, and the unbalanced loads situation is not considered in [17]. Reference [18] presents a data-mining-based intelligent differential protection scheme for the microgrid, but it uses 7 feature components, for example, the differential rate-of-change of frequency, the differential reactive power change with time and so on, but the shortcoming of this method is that it has much data needed to solve including many feature components and high sampling rates. This problem can also be found in [15-17].

Thus, compared with other differential methods, the contributions of this paper are as follows:

(1) This paper extracts the fault feature through solving the parameters of ellipse equation based on the current and voltage fault component. It can only use 5 sampling points to determine the parameters of ellipse which are employed to acquire polarity relationship between the busbar voltage and current.

(2) As for detection criteria, this paper uses \pm 1 to define the feature direction of busbar. It can decrease the difficulty of communication and avoid threshold selection for different operation modes of microgrid.

The rest of this paper is organized as follows. Section 2 employs ellipse equation and minimum least squares to acquire feature cosine to describe the united behavior about voltage and current. The microgrid structure and the reason why the feature cosine can be used are shown in Section 3. Section 4 discusses the change of feature cosine when fault occurs at different locations. Section 5 presents how to use the feature cosine to obtain the differential feature direction to detect faulty section location. Section 6 shows the performance of proposed method including different microgrid operation modes, grounding resistances, and faulty section locations. Moreover, the condition of unbalanced loads is taken into consideration.

\section{Feature Cosine of One Phase in a Bus}

2.1. Mathematical Background. The voltage and current signals in one phase of a bus at time $t$ can be written as

$$
\begin{aligned}
& u(t)=U_{0} \sin (\omega t) \\
& i(t)=I_{0} \sin (\omega t-\phi)
\end{aligned}
$$

where the angle $\phi$ is the delay between $i(t)$ and $u(t) . U_{0}$ and $I_{0}$ are the peak values of $u(t)$ and $i(t)$, respectively. $\omega$ is the angular velocity, $\omega=2 \pi f$. In China system, $f=50 \mathrm{~Hz} \cdot \cos (\phi)$ is defined as the feature cosine.

As for a bus, Figure 1 shows the united behavior of the voltage and current sine signals for one phase at different conditions. This behavior can be modeled using a conic section mathematical equation or, more specifically, the equation of the ellipse. 
By applying (5), the Cartesian form for the equation of the bus ellipse is defined as (4) [19].

$$
\begin{aligned}
& \sin ^{2}(\omega t)+\cos ^{2}(\omega t)=1 \\
& x^{2}(t)-2 \cos (\phi) x(t) y(t)+y^{2}(t)-\sin ^{2}(\phi)=0 \\
& x(t)=\frac{u(t)}{U_{0}}=\sin (\omega t) \\
& y(t)=\frac{i(t)}{I_{0}}=\sin (\omega t-\phi)
\end{aligned}
$$

The equation of the ellipse, for any value of $U_{0}$ and $I_{0}$, is given by

$$
\begin{gathered}
I_{0}^{2} u^{2}(t)-2 U_{0} I_{0} \cos (\phi) u(t) i(t)+U_{0}^{2} i^{2}(t) \\
-U_{0}^{2} I_{0}^{2} \sin ^{2}(\phi)=0
\end{gathered}
$$

Hence, as for a bus, using the geometric properties of (7) can monitor the behavior of voltage and current signals for each phase and identify the moment when potential faults have occurred; besides, this paper proposes that the parameters of the ellipse can be seen as an index to indicate the faulty section location, which is elaborated in the following sections.

2.2. Feature Cosine. According to [20], an ellipse section defined in $\mathrm{R}^{2}$ represents a set of points whose coordinates satisfy the general equation (8), the form of (8) is equivalent to (7), and (8) can be seen as a fitting model to obtain the parameters of (7).

$$
a x^{2}+b x y+c y^{2}+d x+e y+f=0
$$

with the parameters $a$ or $b$ or $c \neq 0$.

Then, (7) and (8) can both be rewritten in matrix form as

$$
\begin{aligned}
f(\boldsymbol{x}) & =\boldsymbol{\alpha} \boldsymbol{x}+1 \\
\boldsymbol{a} & =\left[\begin{array}{lllll}
a & b & c & d & e
\end{array}\right] \\
\boldsymbol{x} & =\left[\begin{array}{lllll}
x_{1} & x_{2} & x_{3} & x_{4} & x_{5}
\end{array}\right]^{\mathrm{T}}=\left[\begin{array}{lllll}
x^{2} & x y & y^{2} & x & y
\end{array}\right]^{\mathrm{T}} \\
& =\left[\begin{array}{lllll}
u^{2}(t) & u(t) i(t) & i^{2}(t) & u(t) & i(t)
\end{array}\right]^{\mathrm{T}}
\end{aligned}
$$

Based on the minimum least squares, a cost function $J_{a}$ can be written as

$$
J_{a}(a, \cdots, e)=\frac{1}{2} \sum_{i=1}^{n}\left[f\left(\boldsymbol{x}_{i}\right)-0\right]^{2}
$$

Hence, the parameters estimation problem is transformed into a simpler problem of finding a local minimizer for $J_{a}$; this problem can be solved by Levenberg-Marquardt algorithm, and it is described in $[16,17]$.

Lastly, the parameters of equation (7) can be obtained from Levenberg-Marquardt algorithm.

$$
\boldsymbol{a}=\boldsymbol{a}^{*}=\left[\begin{array}{lllll}
a^{*} & b^{*} & c^{*} & d^{*} & e^{*}
\end{array}\right]
$$

And the feature $\operatorname{cosine} \cos (\phi)$ can be shown in (13), $\cos (\phi)$ can represent the phase relation between the voltage and current, and it is mentioned that $\cos (\phi)$ for each phase is a constant even in the condition of unbalanced loads if a microgrid operates normally. $\cos (\phi)$ is the index mentioned in Section 2.1. Section 3 will illustrate why $\cos (\phi)$ can be employed to detect microgrid faulty location.

$$
\cos (\phi)=-\frac{b^{*}}{\left(2 \sqrt{a^{*}} \cdot \sqrt{c^{*}}\right)}
$$

\section{Feature Cosine Utilization Reason}

3.1. Microgrid Topology. A modified microgrid based on the topology of CERTS microgrid model [21] is shown in Figure 2(a) and established in Matlab/Simulink. This microgrid is a part of the power distribution system, and it is connected to the utility grid using a transformer $0.4 / 10 \mathrm{kV}$. Each distributed generation (DG) is controlled by improved droop controller $[22,23]$. Table 1 shows each load capacity. The system parameters are given: the power electronic device is the IGBT; the capacities of DGs are all 80kVA; switch frequency is $6 \mathrm{kHz}$; the DC voltage is $800 \mathrm{~V}$; Line: resistance and inductance are $0.642 \Omega / \mathrm{km}$ and $0.083 \mathrm{H} / \mathrm{km}$; the length of Line 1 , Line 2, and Line 3 are $0.3 \mathrm{~km}, 0.2 \mathrm{~km}$, and $0.5 \mathrm{~km}$, respectively.

3.2. Reason. The fault current-limiting strategy is applied for each DG according to [24, 25]. For example, when the microgrid occurs, three-line-ground (LLLG) fault or singleline-ground (LG) fault at $0.2 \mathrm{~s}$, whose faulty location is Line 2 of Figures 2(a), 2(b), and 2(c), shows that the fault currentlimiting strategy, after 0.21 s, can effectively limit each DG fault current into 2 times of the rated current; besides, this strategy can restrain the harmonics and make the frequency of output current and voltage equal to $50 \mathrm{~Hz}$. This is the reason why this paper can use the feature cosine to detect the faulty section.

\section{The Analysis of Microgrid Fault Feature}

4.1. Fault at Line 1. Based on the analysis method from [26], this paper focuses on the current direction. When shortcircuit fault occurs at Line 1 of Figure $2(a), B_{1}, B_{2}, B_{3}, B_{4}$ and $B_{5}$ are bus. Taking $B_{1}$ and $B_{2}$ as an example, Figure 3 shows the current direction of $B_{1}$ and $B_{2}$, which is suitable for the islanded mode and grid connected mode.

When DGs supply power for downstream load shown in Figure 3(a), phase $\phi_{1}$ and $\phi_{2}$ are shown in (14); this is because loads in microgrid are generally inductive loads.

$$
\begin{aligned}
& \phi_{1}=\arg \left(\dot{U}_{1}\right)-\arg \left(\dot{I}_{1}\right)>0^{\circ} \\
& \phi_{2}=\arg \left(\dot{U}_{2}\right)-\arg \left(\dot{I}_{2}\right)>0^{\circ}
\end{aligned}
$$

where $\dot{U}_{1}$ and $\dot{U}_{2}$ are the voltage of $\mathrm{B}_{1}$ and $\mathrm{B}_{2} \cdot \dot{I}_{1}$ and $\dot{I}_{2}$ are the current of $\mathrm{B}_{1}$ and $\mathrm{B}_{2} \cdot \arg \left(\dot{U}_{1}\right)$ means the voltage phase of $\mathrm{B}_{1} \cdot \arg \left(\dot{I}_{1}\right)$ means the current phase of $\mathrm{B}_{1}$. 


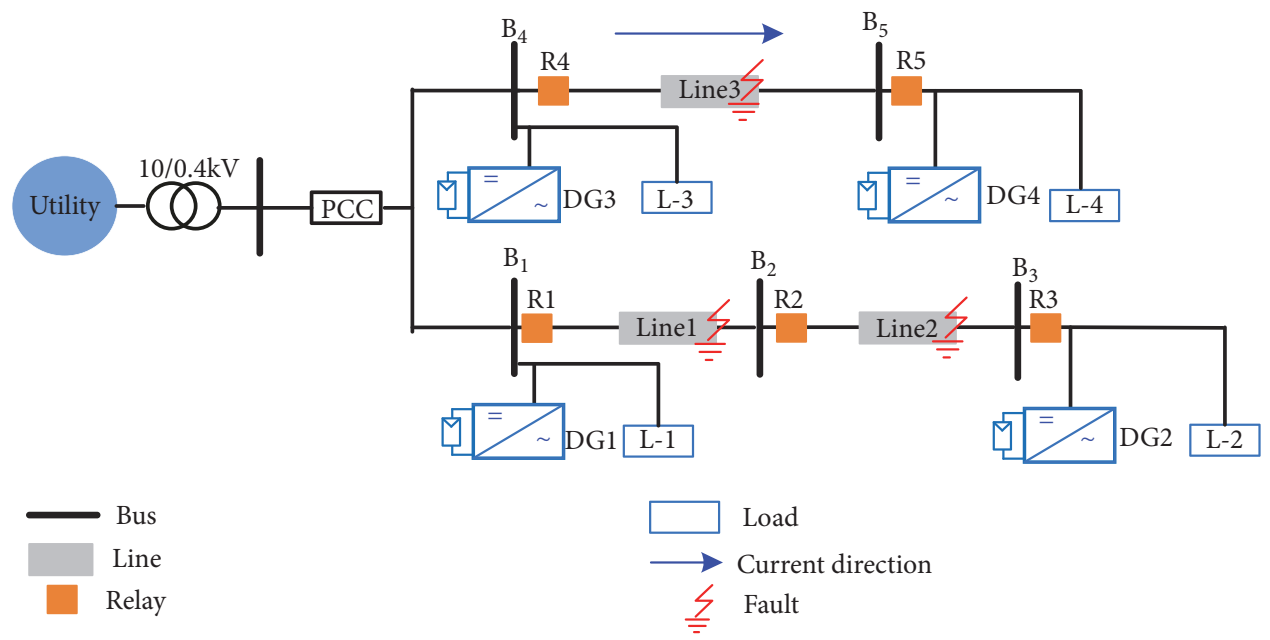

(a)

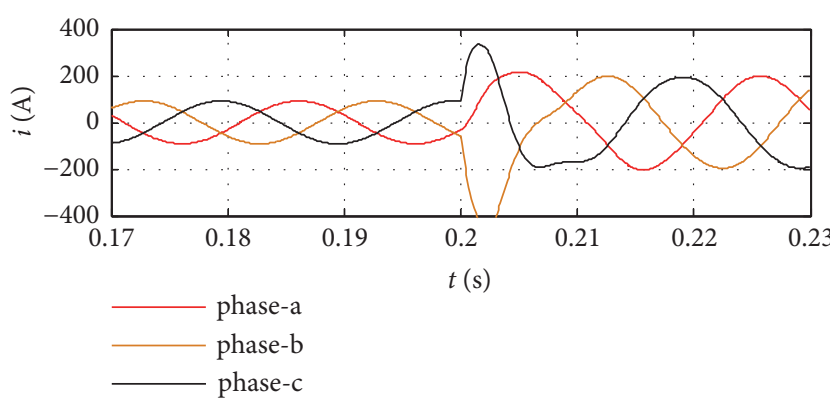

(b)

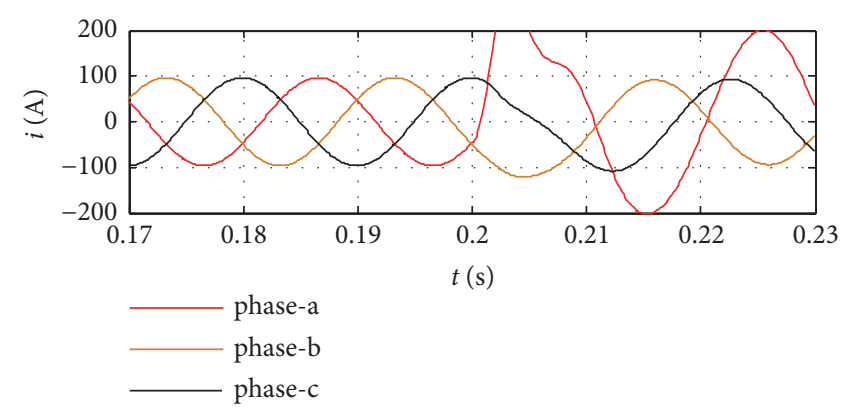

(c)

FIGURE 2: Single line diagram and fault current of microgrid. (a) Single line diagram; (b) fault current by DG1 at LLLG; (c) fault current by DG2 at LG.

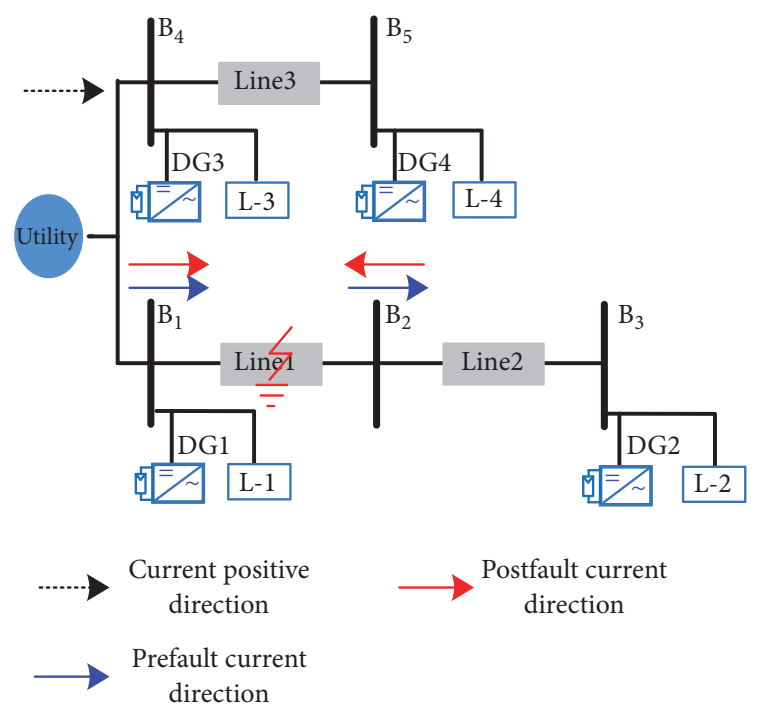

(a)

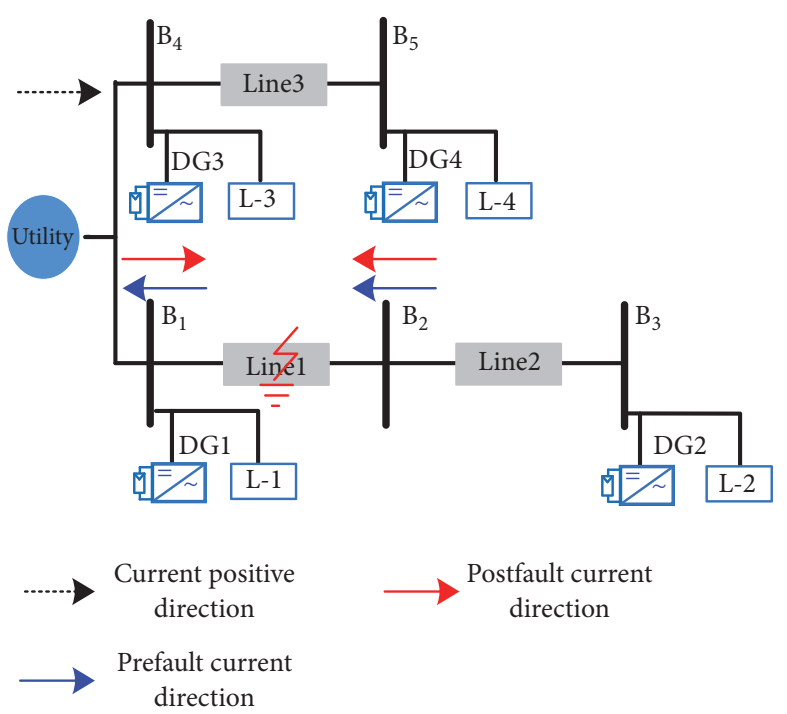

(b)

FIGURE 3: The current direction of $B_{1}$ and $B_{2}$ when fault occurs at Line 1. (a) DGs supply power for downstream load; (b) DGs supply power for upstream load. 
TABLE 1: The capacity of loads.

\begin{tabular}{lcc}
\hline Load Name & Active power in kW & Reactive power in kVar \\
\hline L-1 & 45 & 15 \\
L-2 & 45 & 22.5 \\
L-3 & 35 & 10 \\
L-4 & 45 & 15 \\
\hline
\end{tabular}
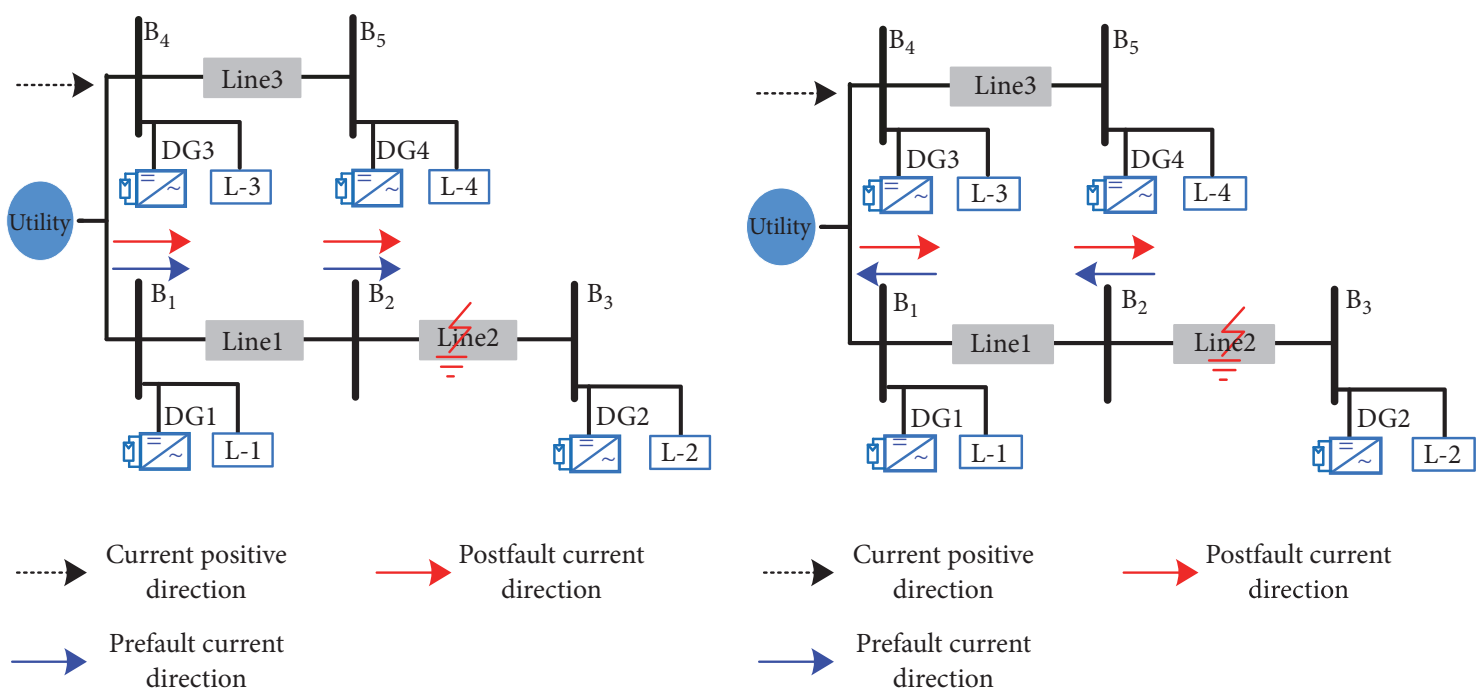

(a)

(b)

FIGURE 4: The current direction of $B_{1}$ and $B_{2}$ when fault occurs at Line 2. (a) DGs supply power for downstream load; (b) DGs supply power for upstream load.

After fault, because the grounding impedance of fault point is obviously less than the load impedance [22], as for current direction, $\mathrm{B}_{1}$ and $\mathrm{B}_{2}$ are both from bus to fault point. Moreover, the voltage phases of $\mathrm{B}_{1}$ and $\mathrm{B}_{2}$ are not changed. Based on this, (15) and (16) can be expressed and present that $\cos \left(\phi_{1}^{\mathrm{f}}\right)$ is positive and $\cos \left(\phi_{2}^{\mathrm{f}}\right)$ is negative when the fault occurs at Line 1 .

$$
\begin{aligned}
\phi_{1}^{\mathrm{f}} & =\arg \left(\dot{U}_{1}^{\mathrm{f}}\right)-\arg \left(\dot{I}_{1}^{\mathrm{f}}\right) \approx \arg \left(\dot{U}_{1}\right)-\arg \left(\dot{I}_{1}\right) \\
& >0^{\circ} \\
\phi_{2}^{\mathrm{f}} & =\arg \left(\dot{U}_{2}^{\mathrm{f}}\right)-\arg \left(\dot{I}_{2}^{\mathrm{f}}\right) \\
& \approx \arg \left(\dot{U}_{2}\right)-\arg \left(\dot{I}_{2}\right)-180^{\circ}<-90^{\circ} \\
\cos \left(\phi_{1}^{\mathrm{f}}\right) & \approx \cos \left(\arg \left(\dot{U}_{1}\right)-\arg \left(\dot{I}_{1}\right)\right)>0 \\
\cos \left(\phi_{2}^{\mathrm{f}}\right) & \approx \cos \left(\arg \left(\dot{U}_{2}\right)-\arg \left(\dot{I}_{2}\right)-180^{\circ}\right)<0
\end{aligned}
$$

where $\phi_{1}^{\mathrm{f}}$ and $\left(\phi_{2}^{\mathrm{f}}\right)$ are the postfault phase of $\mathrm{B}_{1}$ and $\mathrm{B}_{2}$.

When the DGs supply power for upstream load, the current directions at $B_{1}$ and $B_{2}$ are shown in Figure 3(b). Through analyzing, when the fault occurs at Line $1, \cos \left(\phi_{1}^{\mathrm{f}}\right)$ is positive and $\cos \left(\phi_{2}^{\mathrm{f}}\right)$ is negative.
4.2. Fault at Line 2. When the fault occurs at Line 2 of Figure 2(a), the current direction of $B_{1}$ and $B_{2}$ is shown in Figure 4.

When the DGs supply power for downstream loads shown in Figure 4(a) and the fault occurs at Line 2, the current directions, the current directions of $B_{1}$ and $B_{2}$ are both from bus to fault point because the load impedance is bigger than the grounding impedance [22]. $\cos \left(\phi_{1}^{\mathrm{f}}\right)$ and $\cos \left(\phi_{2}^{\mathrm{f}}\right)$ can be shown in

$$
\begin{aligned}
& \cos \left(\phi_{1}^{\mathrm{f}}\right) \approx \cos \left(\arg \left(\dot{U}_{1}\right)-\arg \left(\dot{I}_{1}\right)\right)>0 \\
& \cos \left(\phi_{2}^{\mathrm{f}}\right) \approx \cos \left(\arg \left(\dot{U}_{2}\right)-\arg \left(\dot{I}_{2}\right)\right)>0
\end{aligned}
$$

Similarly, if the DGs supply power for downstream load shown in Figure $4(\mathrm{~b}), \cos \left(\phi_{1}^{\mathrm{f}}\right)$ and $\cos \left(\phi_{2}^{\mathrm{f}}\right)$ are both positive when fault occurs at Line 2.

4.3. Fault at Line 3. The current direction of $\mathrm{B}_{1}$ and $\mathrm{B}_{2}$ is shown in Figure 5 when the fault occurs at Line 3 of Figure 2(a). There are two situations as follows because the distance is relatively far from fault point to $B_{2}$.

(I) The grounding impedance is relatively small; that is, the effect of fault point on $B_{2}$ is serious. And the current direction of $B_{1}$ and $B_{2}$ will be both from bus to fault point; these directions are opposite to that in prefault and are shown 


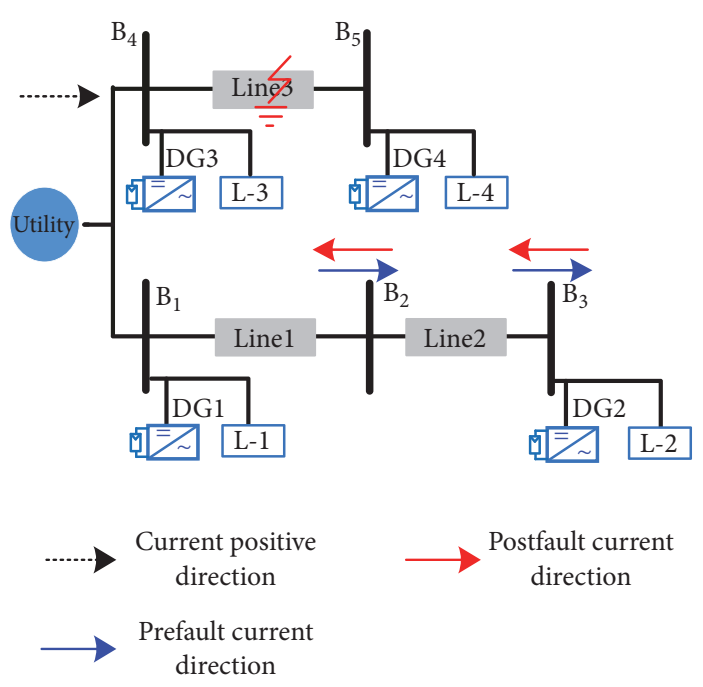

(a)

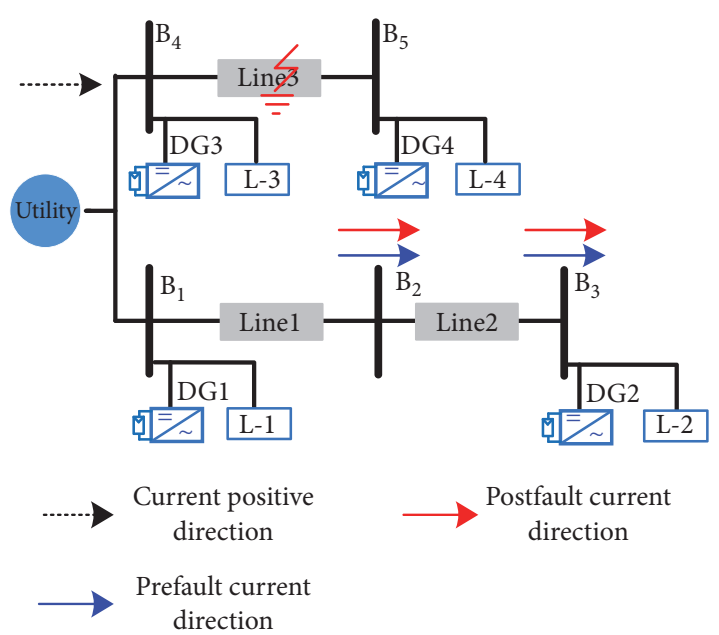

(b)

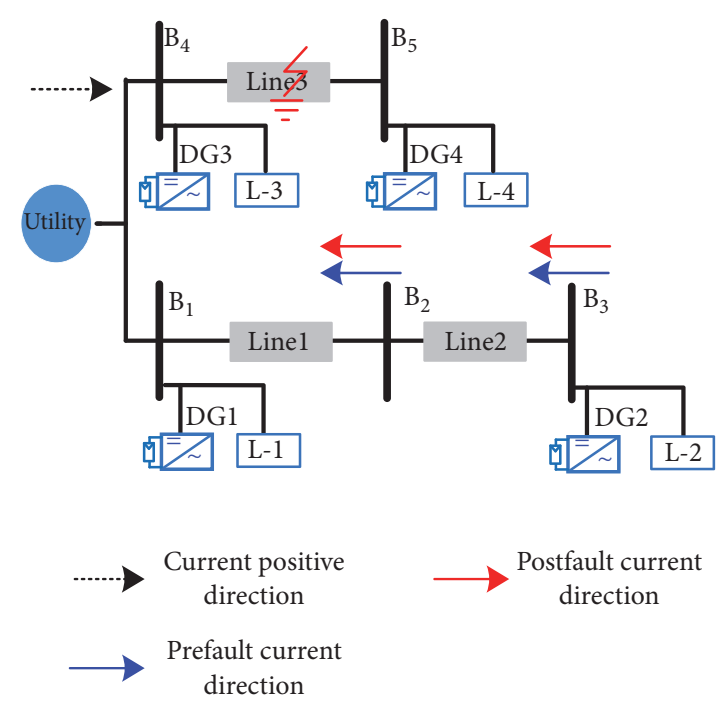

(c)

Figure 5: The current direction of $B_{1}$ and $B_{2}$ when fault occurs at Line 3. (a) DGs supply power for downstream load when the effect is serious; (b) DGs supply power for downstream load when the effect is mild; (c) DGs supply power for upstream load.

in Figure 5(a). (18) shows their feature cosine; they are both negative.

$$
\begin{aligned}
& \cos \left(\phi_{1}^{\mathrm{f}}\right) \approx \cos \left(\arg \left(\dot{U}_{1}\right)-\arg \left(\dot{I}_{1}\right)-180^{\circ}\right)<0 \\
& \cos \left(\phi_{2}^{\mathrm{f}}\right) \approx \cos \left(\arg \left(\dot{U}_{2}\right)-\arg \left(\dot{I}_{2}\right)-180^{\circ}\right)<0
\end{aligned}
$$

(II) When the effect of fault point on $B_{2}$ is mild, the current direction of $\mathrm{B}_{1}$ and $\mathrm{B}_{2}$ can be maintained; these are same as that in prefault shown in Figure 5(b). The $\cos \left(\phi_{1}^{\mathrm{f}}\right)$ and $\cos \left(\phi_{2}^{\mathrm{f}}\right)$ are both positive.

Similarly, if the DGs supply power for upstream load shown in Figure 5(c), there are also two situations according to the effect of fault point on $B_{2}$. And $\cos \left(\phi_{1}^{f}\right)$ and $\cos \left(\phi_{2}^{\mathrm{f}}\right)$ will be both negative in these two situations.

In summary, no matter how the initial current direction changes in bus, $\cos \left(\phi_{1}^{\mathrm{f}}\right)$ is positive and $\cos \left(\phi_{2}^{\mathrm{f}}\right)$ is negative when the fault occurs at the section between $B_{1}$ and $B_{2}$. Moreover, there are two situations when the fault does not occur at the area between $B_{1}$ and $B_{2}$ : (1) $\cos \left(\phi_{1}^{\mathrm{f}}\right)$ and $\cos \left(\phi_{2}^{\mathrm{f}}\right)$ are both positive and $(2) \cos \left(\phi_{1}^{\mathrm{f}}\right)$ and $\cos \left(\phi_{2}^{\mathrm{f}}\right)$ are both negative. These can be clearly shown in Table 2 where "+" is positive, "-" is negative. The difference of feature cosine can be utilized to detect the faulty section in the next section.

\section{Protection Methodology}

Firstly, it is mentioned that the relays at the ends of a bus are considered and not at the ends of the line; this is because it can reduce the number of relays being used; however, the circuit breakers need to be installed at the ends of the line for isolating a fault. 
TABLE 2: The direction of feature cosine of $B_{1}$ and $B_{2}$.

\begin{tabular}{llll}
\hline Faulty part & $\mathrm{B}_{1}$ & & \\
\hline Line1 & + & $\mathrm{B}_{2}$ \\
\hline \multirow{2}{*}{ Line2 } & + & + \\
& - & - \\
\hline \multirow{2}{*}{ Line3 } & + & + \\
& - & - \\
\hline
\end{tabular}

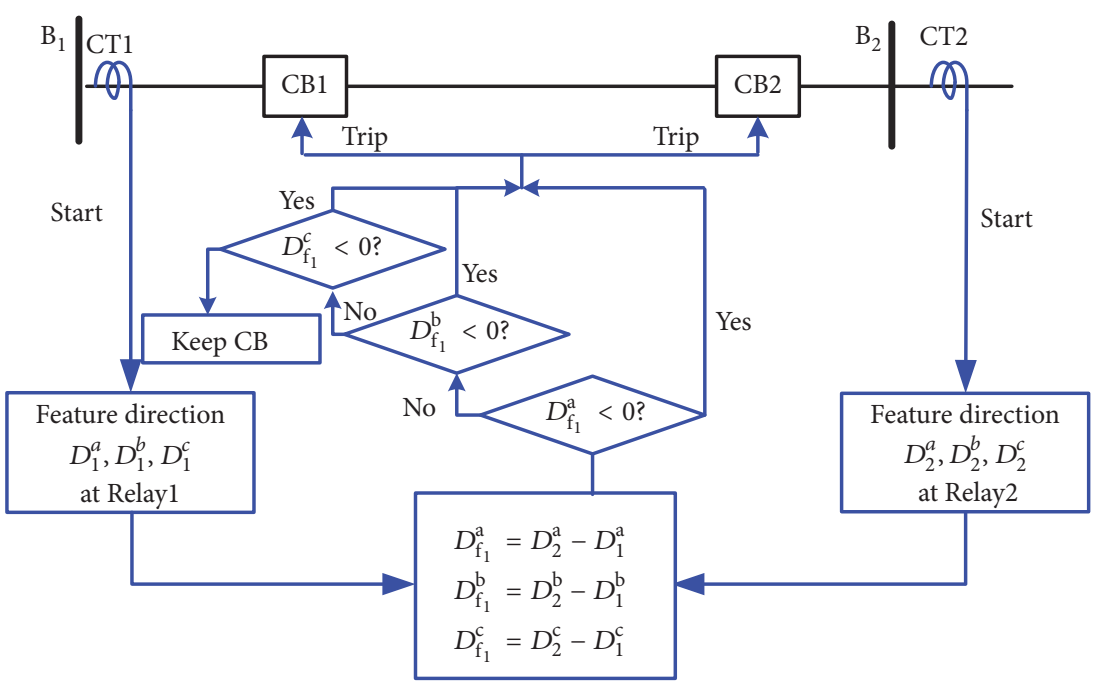

FIGURE 6: The procedures of this paper's proposed method.

Then, it is presented how to obtain the feature direction (D) of each bus through feature cosine.

Step 1. $u_{n}^{w}(t), u_{n+1}^{w}(t), i_{n}^{w}(t)$, and $i_{n+1}^{w}(t)$ are retrieved at $\mathrm{B}_{\mathrm{n}}$ and $\mathrm{B}_{\mathrm{n}+1}, u_{n}^{w}(t)$ and $i_{n}^{w}(t)$ are the normalized voltage and current of phase-w of $\mathrm{B}_{\mathrm{n}}, u_{n+1}^{w}(t)$ and $i_{n+1}^{w}(t)$ are the normalized voltage and current of phase-w of $\mathrm{B}_{\mathrm{n}+1}, \mathrm{w}$ is a or $\mathrm{b}$ or $\mathrm{c}, n$ is the number of bus, and $n$ is equal to 1,2 and 4 .

Step 2. As for $\mathrm{B}_{\mathrm{n}}$, according to Levenberg-Marquardt algorithm, the parameters of bus ellipse equation $\boldsymbol{\alpha}_{n}^{w}$ can be calculated. $\boldsymbol{\alpha}_{n}^{w}$ can represent the behavior of voltage and current signals.

$$
\boldsymbol{a}_{n}^{w}=\left[\begin{array}{lllll}
a_{n}^{w} & b_{n}^{w} & c_{n}^{w} & d_{n}^{w} & e_{n}^{w}
\end{array}\right]
$$

Step 3. Similarly, as for $\mathrm{B}_{\mathrm{n}+1}$, the parameters of line ellipse equation $\boldsymbol{a}_{n+1}^{w}$ can be obtained.

$$
\boldsymbol{a}_{n+1}^{w}=\left[\begin{array}{lllll}
a_{n+1}^{w} & b_{n+1}^{w} & c_{n+1}^{w} & d_{n+1}^{w} & e_{n+1}^{w}
\end{array}\right]
$$

Step 4. $\cos \left(\phi_{n}^{w}\right)$ and $\cos \left(\phi_{n+1}^{w}\right)$ are calculated, $\cos \left(\phi_{n}^{w}\right)$ and $\cos \left(\phi_{n+1}^{w}\right)$ are the feature cosine of $B_{n}$ and $B_{n+1}$.

$$
\begin{aligned}
\cos \left(\phi_{n}^{w}\right) & =-\frac{b_{n}^{w}}{\left(2 \sqrt{a_{n}^{w}} \sqrt{c_{n}^{w}}\right)} \\
\cos \left(\phi_{n+1}^{w}\right) & =-\frac{b_{n+1}^{w}}{\left(2 \sqrt{a_{n+1}^{w}} \sqrt{c_{n+1}^{w}}\right)}
\end{aligned}
$$

Step 5. $D_{n}^{w}, D_{n+1}^{w}$, and $D_{c n}^{w}$ can be obtained by the following equations. $D_{n}^{w}$ and $D_{n+1}^{w}$, which can show the fault current direction of bus, are the feature direction of $B_{n}$ and $B_{n+1}$, and $D_{c n}^{w}$ is the differential direction.

$$
\begin{gathered}
D_{n}^{w}= \begin{cases}1, & \cos \left(\phi_{n}^{w}\right)>0 \\
-1, & \cos \left(\phi_{n}^{w}\right)<0,\end{cases} \\
D_{n+1}^{w}= \begin{cases}1, & \cos \left(\phi_{n+1}^{w}\right)>0 \\
-1, & \cos \left(\phi_{n+1}^{w}\right)<0\end{cases} \\
D_{\mathrm{c} n}^{w}=D_{n+1}^{w}-D_{n}^{w}
\end{gathered}
$$

Lastly, if $D_{c n}^{w}<0$, the section between $B_{n}$ and $B_{n+1}$ is judged as faulty section; if $D_{c n}^{w} \geqq 0$, the section between $B_{n}$ and $B_{n+1}$ is judged as healthy section. Taking $B_{1}$ and $B_{2}$ as an example, the procedures of this paper's proposed method can be shown clearly in Figure 6.

\section{Simulation Results}

In order to prove the effectiveness of the proposed method in this paper, different fault conditions are simulated through Matlab/Simulink for the microgrid shown in Figure 2(a), and conditions for the fault study are explained as follows.

(1) Faulty resistances $\left(R_{\mathrm{f}}\right): 0.01,0.1,0.2,0.3,0.5,1,5,10 \Omega$. 
TABLE 3: The feature cosine of each bus and results with different grounding resistances.

\begin{tabular}{|c|c|c|c|c|}
\hline$R_{\mathrm{f}}$ & $P$ & {$\left[\mathrm{~B}_{1}, \mathrm{~B}_{2}, \mathrm{~B}_{3}, \mathrm{~B}_{4}, \mathrm{~B}_{5}\right]$} & $\begin{array}{r}\text { Each } P \\
\text { result }\end{array}$ & $\begin{array}{l}\text { Final } \\
\text { result }\end{array}$ \\
\hline \multirow{3}{*}{$0.01 \Omega$} & $\mathrm{a}$ & {$[0.954,-0.990,-0.982,-0.859,-0.729]$} & $\mathrm{B}_{1}-\mathrm{B}_{2}$ & \multirow{3}{*}{$\mathrm{B}_{1}-\mathrm{B}_{2}$} \\
\hline & $\mathrm{b}$ & {$[0.998,0.999,0.999,-1.007,-1.009]$} & healthy & \\
\hline & $\mathrm{c}$ & {$[0.999,0.999,0.999,-0.997,-0.995]$} & healthy & \\
\hline \multirow{3}{*}{$0.1 \Omega$} & a & {$[0.961,-0.986,-0.978,-0.904,-0.797]$} & $\mathrm{B}_{1}-\mathrm{B}_{2}$ & \multirow{3}{*}{$\mathrm{B}_{1}-\mathrm{B}_{2}$} \\
\hline & $\mathrm{b}$ & {$[0.998,0.998,0.998,-0.991,-0.987]$} & healthy & \\
\hline & c & {$[0.998,0.998,0.999,-0.992,-0.989]$} & healthy & \\
\hline \multirow{3}{*}{$0.5 \Omega$} & $\mathrm{a}$ & {$[0.999,-1.000,-0.999,-0.997,-0.997]$} & $\mathrm{B}_{1}-\mathrm{B}_{2}$ & \multirow{3}{*}{$\mathrm{B}_{1}-\mathrm{B}$} \\
\hline & $\mathrm{b}$ & {$[-0.891,-0.894,-0.896,0.720,0.699]$} & healthy & \\
\hline & c & {$[-0.958,-0.960,-0.962,0.925,0.919]$} & healthy & \\
\hline \multirow{3}{*}{$2 \Omega$} & a & {$[0.936,-0.979,-0.960,-0.897,-0.767]$} & $\mathrm{B}_{1}-\mathrm{B}_{2}$ & \multirow{3}{*}{$\mathrm{B}_{1}-\mathrm{B}_{2}$} \\
\hline & $\mathrm{b}$ & {$[0.999,0.999,1.000,-0.994,-0.993]$} & healthy & \\
\hline & c & {$[1.000,1.000,1.001,-0.996,-0.994]$} & healthy & \\
\hline \multirow{3}{*}{$10 \Omega$} & a & {$[0.927,-0.974,-0.952,-0.888,-0.752]$} & $\mathrm{B}_{1}-\mathrm{B}_{2}$ & \multirow{3}{*}{$\mathrm{B}_{1}-\mathrm{B}_{2}$} \\
\hline & $\mathrm{b}$ & {$[0.999,0.999,0.999,-0.995,-0.993]$} & healthy & \\
\hline & c & {$[0.999,0.999,1.000,-0.998,-0.997]$} & healthy & \\
\hline
\end{tabular}

(2) Different faulty types $\left(F_{t}\right)$ : single-line-ground (LG), double-line-ground (LLG), line-line (LL), and three-lineground (LLLG), where LG(a) means the single-line-ground whose faulty phase is phase-a.

(3) Faulty section $\left(F_{\mathrm{L}}\right)$ : Line 1 , Line 2 , and Line 3.

(4) Different microgrid operation modes $\left(O_{m}\right)$ : islanded and grid connected mode.

(5) Unbalanced loads: each phase capacity of load is changed.

(6) Noise influence: the signal to noise ratio (SNR) is set as $50 \mathrm{db}, 20 \mathrm{db}$, and $5 \mathrm{db}$.

6.1. Different Grounding Resistances. When the microgrid shown in Figure 2(a) is operated in islanded mode, LG fault is supposed to happen in Line 1 at $t=0.2 \mathrm{~s}$; that is, faulty section is between $B_{1}$ and $B_{2}$ labelled $B_{1}-B_{2}$. Faulty conditions include that faulty phase is phase-a and grounding resistances are set to $0.01 \Omega, 0.5 \Omega, 0.1 \Omega, 2 \Omega$, and $10 \Omega$, respectively. Then Table 3 gives the feature cosine of each bus and judgment results after implementing this paper's method; $P$ is phase sequence.

Take grounding resistance $0.5 \Omega$ as an example, Figure 7 gives the voltage and current of $B_{1}$ and $B_{2}$, and Figure 8 shows the bus ellipses of each phase of $B_{1}$ and $B_{2}$. Figure 7 illustrates that the faulty phase voltage direction of $B_{1}$ is same as that of $B_{2}$ and the faulty phase current direction of $B_{1}$ is opposite to that of $B_{2}$, which is illustrated obviously in Figure 8 .

Then, as for phase-a, from Table 3 and this paper's method, the feature cosines from $B_{1}$ to $B_{5}$ are 0.999, $1.000,-0.999,-0.997$, and -0.997 , respectively. So, the feature directions from $B_{1}$ to $B_{5}$ are $1,-1,-1,-1$, and -1 , respectively; that is, their differential directions are $-2,0,0,0$, respectively. Similarly, as for phase-b and phase-c, their differential directions are all 0 . Hence, the faulty section is between $B_{1}$ and $\mathrm{B}_{2}$; this result is consistent with the actual fault. Lastly, from
Table 3 we can find that this paper's method can detect fault part effectively in different grounding resistances.

6.2. Different Faulty Types. When the microgrid is operated in islanded mode, different faulty types, including LG(b), LLG(ab), LL(bc), and LLLG, are supposed to happen in Line 1 at $0.2 \mathrm{~s}$ with grounding resistance $0.1 \Omega$; that is, faulty section is $B_{1}-B_{2}$. Then, Table 4 gives the feature cosine of each bus and judgment results; it shows that the proposed method cannot be influenced by different faulty types.

6.3. Different Faulty Section Locations. The islanded microgrids are simulated at $0.2 \mathrm{~s}$ with different faulty section locations, including $\mathrm{B}_{1}-\mathrm{B}_{2}, \mathrm{~B}_{2}-\mathrm{B}_{3}$, and $\mathrm{B}_{4}-\mathrm{B}_{5}$. The fault conditions include fault type LG whose faulty phase is phase-c or phase-a; grounding resistances is $0.3 \Omega$ or $10 \Omega$. Then, Table 5 illustrates that this paper's method can detect different fault parts. It is mentioned that the feature cosine is consist with the analysis in Section 4.3 when the grounding resistance is $10 \Omega$ and faulty section location is $B_{4}-B_{5}$.

6.4. Grid Connected Operation Mode. When the microgrid is operated at grid connected mode, different faults are supposed to happen including different faulty section locations, types, and grounding resistances. Table 6 gives the judgments and shows that this paper's method can detect different faults in grid connected operation mode; besides, the protection scheme cannot be changed compared with islanded mode.

6.5. Unbalanced Loads. In order to prove the effectiveness of proposed method in the condition of the unbalanced loads, the capacity of load L-2 in Figure 2(a) is set as follows: phasea: the active power and reactive power are $19 \mathrm{~kW}$ and $8 \mathrm{~kW}$; phase-b: the active power and reactive power are $17 \mathrm{~kW}$ and 


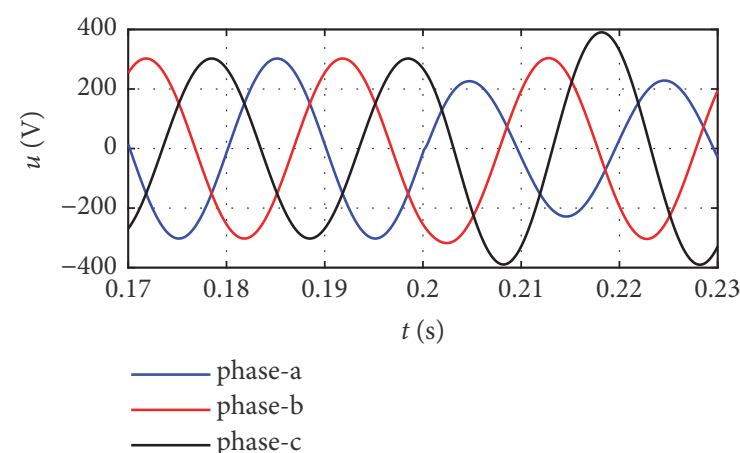

(a) $B_{1}$ voltage
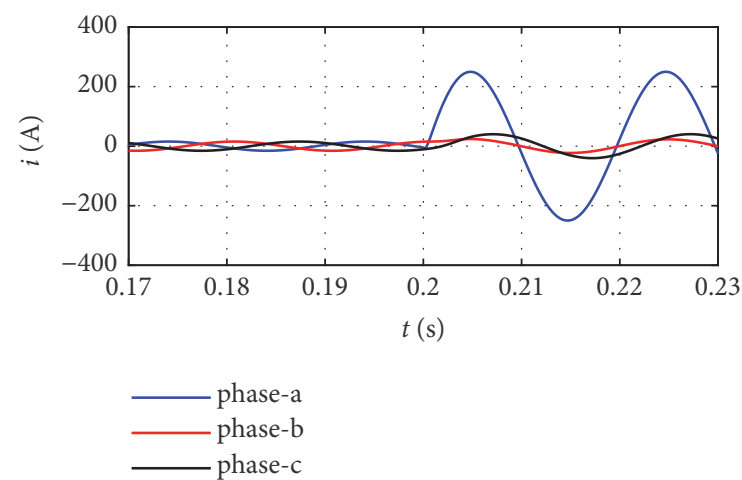

(c) $B_{1}$ current

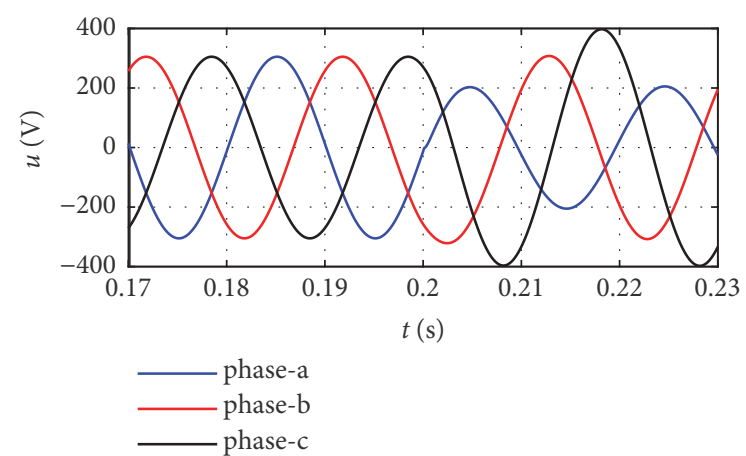

(b) $B_{2}$ voltage

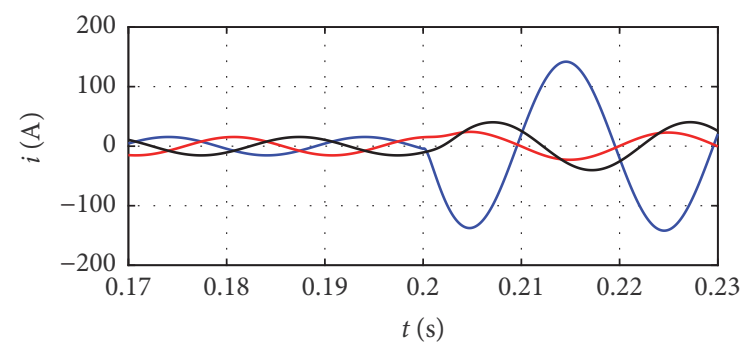

phase-a
phase-b
phase-c

(d) $B_{2}$ current

Figure 7: The voltage and current of $B_{1}$ and $B_{2}$ when fault occurs at Line 1. (a) $B_{1}$ voltage; (b) $B_{2}$ voltage; (c) $B_{1}$ current; (d) $B_{2}$ current.

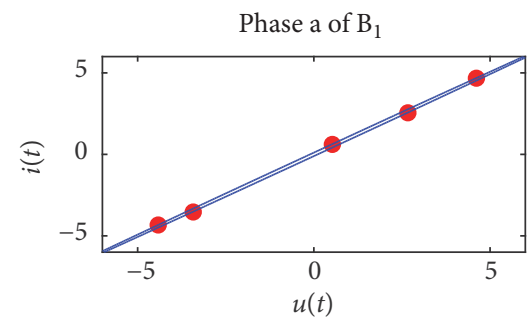

Phase a of $B_{2}$

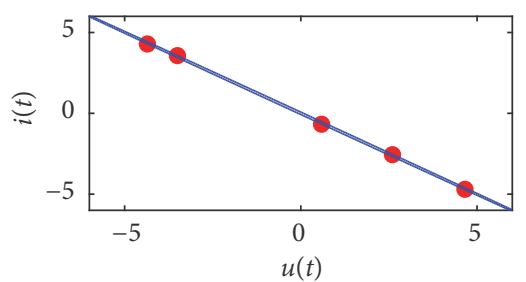

- Sampling point

Fitting curve
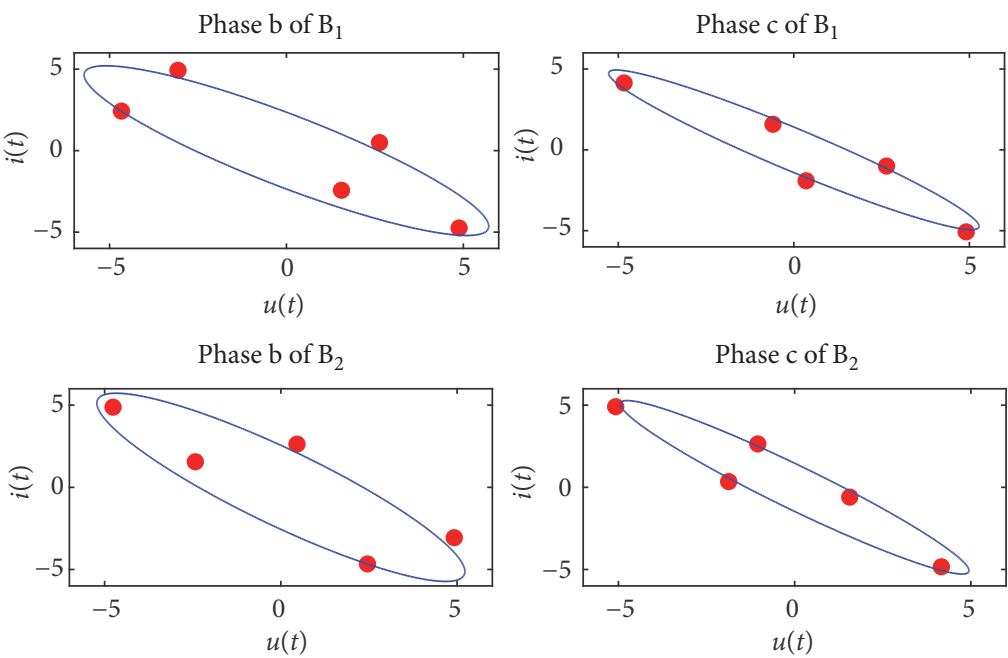

Figure 8: The bus ellipse of $B_{1}$ and $B_{2}$ for different phases. (a) Phase-a; (b) phase-b; (c) phase-c.

$7 \mathrm{~kW}$; phase-c: the active power and reactive power are $10 \mathrm{~kW}$ and $8 \mathrm{~kW}$.

When different faults are supposed to happen in the microgrid, Table 7 gives the feature cosine of each bus and judgment results. When faulty condition is that faulty section location is $B_{1}-B_{2}$, grounding resistance is $0.1 \Omega$, operation mode is islanded, and faulty type is LG (a), Figure 9 is the current of $B_{2}$ and the bus ellipses of $B_{1}$ and $B_{2}$. From Figure 9 and Table 7 , this paper method can achieve the faulty section location detection in the condition of the unbalanced loads. 
TABLE 4: The feature cosine of each bus and judgment results with different faulty types.

\begin{tabular}{|c|c|c|c|c|}
\hline$F_{\mathrm{t}}$ & $P$ & {$\left[\mathrm{~B}_{1}, \mathrm{~B}_{2}, \mathrm{~B}_{3}, \mathrm{~B}_{4}, \mathrm{~B}_{5}\right]$} & $\begin{array}{r}\text { Each } P \\
\text { result }\end{array}$ & $\begin{array}{l}\text { Final } \\
\text { result }\end{array}$ \\
\hline \multirow{3}{*}{$\begin{array}{l}\text { LG } \\
\text { (b) }\end{array}$} & $\mathrm{a}$ & {$[1.003,1.003,1.003,-1.008,-1.012]$} & healthy & \multirow{3}{*}{$\mathrm{B}_{1}-\mathrm{B}_{2}$} \\
\hline & $\mathrm{b}$ & {$[0.928,-0.915,-0.871,-1.100,-1.084]$} & $\mathrm{B}_{1}-\mathrm{B}_{2}$ & \\
\hline & c & {$[1.002,1.002,1.002,-0.991,-0.9867]$} & $\mathrm{B}_{1}-\mathrm{B}_{2}$ & \\
\hline \multirow{3}{*}{$\begin{array}{l}\text { LLG } \\
(\mathrm{ab})\end{array}$} & $\mathrm{a}$ & {$[0.957,-0.946,-0.915,-0.994,-0.970]$} & $\mathrm{B}_{1}-\mathrm{B}_{2}$ & \multirow{3}{*}{$\mathrm{B}_{1}-\mathrm{B}_{2}$} \\
\hline & $\mathrm{b}$ & {$[0.672,-0.508,-0.380,-0.829,-0.614]$} & $\mathrm{B}_{1}-\mathrm{B}_{2}$ & \\
\hline & c & {$[0.998,0.997,0.997,1.004,1.006]$} & healthy & \\
\hline \multirow{3}{*}{$\begin{array}{l}\mathrm{LL} \\
(\mathrm{bc})\end{array}$} & $\bar{a}$ & {$[0.401,0.631,0.715,0.113,0.897]$} & healthy & \multirow{3}{*}{$\mathrm{B}_{1}-\mathrm{B}_{2}$} \\
\hline & $\mathrm{b}$ & {$[0.953,-0.941,-0.958,-0.977,-0.900]$} & $\mathrm{B}_{1}-\mathrm{B}_{2}$ & \\
\hline & c & {$[0.956,-0.943,-0.957,-0.978,-0.909]$} & $\mathrm{B}_{1}-\mathrm{B}_{2}$ & \\
\hline \multirow{3}{*}{ LLL } & $\bar{a}$ & {$[0.836,-0.636,-0.473,-0.949,-0.869]$} & $\mathrm{B}_{1}-\mathrm{B}_{2}$ & \multirow{3}{*}{$\mathrm{B}_{1}-\mathrm{B}_{2}$} \\
\hline & $\mathrm{b}$ & {$[0.609,-0.696,-0.497,-0.852,-0.642]$} & $\mathrm{B}_{1}-\mathrm{B}_{2}$ & \\
\hline & c & {$[0.999,-0.866,-0.770,-1.040,-1.010]$} & $\mathrm{B}_{1}-\mathrm{B}_{2}$ & \\
\hline
\end{tabular}

TABLE 5: The feature cosine of each bus and judgment results in different faulty section locations.

\begin{tabular}{|c|c|c|c|c|}
\hline $\begin{array}{l}F_{\mathrm{t}} \\
R_{\mathrm{f}} \\
F_{\mathrm{L}} \\
\end{array}$ & $P$ & {$\left[\mathrm{~B}_{1}, \mathrm{~B}_{2}, \mathrm{~B}_{3}, \mathrm{~B}_{4}, \mathrm{~B}_{5}\right]$} & $\begin{array}{r}\text { Each } P \\
\text { result }\end{array}$ & $\begin{array}{l}\text { Final } \\
\text { result }\end{array}$ \\
\hline $\mathrm{LG}(\mathrm{c})$ & a & {$[0.998,0.999,0.999,-0.988,-0.985]$} & healthy & \multirow{3}{*}{$\mathrm{B}_{1}-\mathrm{B}_{2}$} \\
\hline $0.3 \Omega$ & $\mathrm{b}$ & {$[0.998,0.999,0.999,-0.990,-0.987]$} & healthy & \\
\hline $\mathrm{B}_{1}-\mathrm{B}_{2}$ & $\mathrm{c}$ & {$[0.883,-0.940,-0.906,-0.797,-0.656]$} & $\mathrm{B}_{1}-\mathrm{B}_{2}$ & \\
\hline $\mathrm{LG}(\mathrm{c})$ & $\mathrm{a}$ & {$[0.985,0.990,0.992,-0.972,-0.963]$} & healthy & \multirow{3}{*}{$\mathrm{B}_{2}-\mathrm{B}_{3}$} \\
\hline $0.3 \Omega$ & $\mathrm{b}$ & {$[0.988,0.992,0.993,-0.974,-0.965]$} & healthy & \\
\hline $\mathrm{B}_{2}-\mathrm{B}_{3}$ & $\mathrm{c}$ & {$[0.766,0.922,-0.979,-0.739,-0.627]$} & $\mathrm{B}_{2}-\mathrm{B}_{3}$ & \\
\hline $\mathrm{LG}(\mathrm{c})$ & a & {$[-0.821,-0.806,-0.796,0.835,0.850]$} & healthy & \multirow{3}{*}{$\mathrm{B}_{4}-\mathrm{B}_{5}$} \\
\hline $0.3 \Omega$ & $\mathrm{b}$ & {$[-0.847,-0.833,-0.825,0.847,0.861]$} & healthy & \\
\hline $\mathrm{B}_{4}-\mathrm{B}_{5}$ & c & {$[-0.618,-0.472,-0.374,0.866,-0.9461]$} & $\mathrm{B}_{4}-\mathrm{B}_{5}$ & \\
\hline LG(a) & $\mathrm{a}$ & {$[0.909,-0.956,-0.922,-0.525,-0.345]$} & $\mathrm{B}_{1}-\mathrm{B}_{2}$ & \multirow{3}{*}{$\mathrm{B}_{1}-\mathrm{B}_{2}$} \\
\hline $10 \Omega$ & $\mathrm{b}$ & {$[0.998,0.998,0.998,-0.996,-0.994]$} & healthy & \\
\hline $\mathrm{B}_{1}-\mathrm{B}_{2}$ & c & {$[0.999,1.000,1.000,-0.993,-0.992]$} & healthy & \\
\hline LG(a) & a & {$[0.544,0.780,-0.993,-0.486,-0.324]$} & $\mathrm{B}_{2}-\mathrm{B}_{3}$ & \multirow{3}{*}{$\mathrm{B}_{2}-\mathrm{B}_{3}$} \\
\hline $10 \Omega$ & $\mathrm{b}$ & {$[0.993,0.995,0.996,-0.985,-0.980]$} & healthy & \\
\hline $\mathrm{B}_{2}-\mathrm{B}_{3}$ & $\mathrm{c}$ & {$[0.994,0.996,0.997,-0.992,-0.989]$} & healthy & \\
\hline LG(a) & $\mathrm{a}$ & {$[-0.210,-0.105,-0.034,0.795,-0.985]$} & $\mathrm{B}_{4}-\mathrm{B}_{5}$ & \multirow{3}{*}{$\mathrm{B}_{4}-\mathrm{B}_{5}$} \\
\hline $10 \Omega$ & $\mathrm{b}$ & {$[-0.923,-0.909,-0.899,0.942,0.953]$} & healthy & \\
\hline $\mathrm{B}_{4}-\mathrm{B}_{5}$ & $\mathrm{c}$ & {$[-0.922,-0.910,-0.899,0.931,0.939]$} & healthy & \\
\hline
\end{tabular}

6.6. Noise Influence. In fact, the elliptical representation of the behavior of both voltage and current signals should consider the existence of the noise, which is inherent in the processes of generation, transmission, or even disturbances related to digital recorders. Hence, in order to implement the proposed method effectively, the wavelet denoising method is employed [27]. It is embedded in Step 1 of Section 5.

When different faults with different SNR including 50db and $5 \mathrm{db}$ are supposed to happen in the microgrid, Table 8 shows that this paper method after adding wavelet denoising method can detect faulty section locations in different SNR including $50 \mathrm{db}$ and $5 \mathrm{db}$.
6.7. Looped Microgrid. When different faults are supposed to happen in the looped microgrid shown in Figure 10, Table 9 gives the feature cosine of each bus and judgment results. From Table 9, we can know that this paper method can achieve the faulty section location detection in different faulty conditions for looped microgrid.

6.8. Sample Microgrid. When different faults are supposed to happen in the looped microgrid shown in Figure 11, Table 10 gives the feature cosine of each bus and judgment results. From Table 10, we can know that this paper method can 
TABLE 6: The feature cosine of each bus and judgment results in grid connected operation mode.

\begin{tabular}{|c|c|c|c|c|}
\hline $\begin{array}{l}F_{\mathrm{t}} \\
R_{\mathrm{f}} \\
F_{\mathrm{L}}\end{array}$ & $P$ & {$\left[\mathrm{~B}_{1}, \mathrm{~B}_{2}, \mathrm{~B}_{3}, \mathrm{~B}_{4}, \mathrm{~B}_{5}\right]$} & $\begin{array}{r}\text { Each } P \\
\text { result }\end{array}$ & $\begin{array}{l}\text { Final } \\
\text { result }\end{array}$ \\
\hline LG(a) & a & {$[0.054,-0.540,-0.271,-0.985,-0.974]$} & $\mathrm{B}_{1}-\mathrm{B}_{2}$ & \multirow{3}{*}{$\mathrm{B}_{1}-\mathrm{B}_{2}$} \\
\hline $0.01 \Omega$ & $\mathrm{b}$ & {$[-0.5926,1.000,1.000,0.4800,0.340]$} & healthy & \\
\hline $\mathrm{B}_{1}-\mathrm{B}_{2}$ & c & {$[-0.443,-0.013,0.842,0.256,0.421]$} & healthy & \\
\hline LG(b) & a & {$[0.191,0.780,0.901,0.768,0.822]$} & healthy & \multirow{3}{*}{$\mathrm{B}_{1}-\mathrm{B}_{2}$} \\
\hline $0.2 \Omega$ & $\mathrm{b}$ & {$[0.507,-0.909,-0.840,-0.984,-0.981]$} & $\mathrm{B}_{1}-\mathrm{B}_{2}$ & \\
\hline $\mathrm{B}_{1}-\mathrm{B}_{2}$ & c & {$[0.181,0.764,0.895,0.713,0.782]$} & healthy & \\
\hline LLG(ac) & $\mathrm{a}$ & {$[0.107,0.999,-0.829,-0.656,-0.021]$} & $\mathrm{B}_{2}-\mathrm{B}_{3}$ & \multirow{3}{*}{$\mathrm{B}_{2}-\mathrm{B}_{3}$} \\
\hline $0.5 \Omega$ & $\mathrm{b}$ & {$[0.112,0.875,0.940,0.709,0.759]$} & healthy & \\
\hline $\mathrm{B}_{2}-\mathrm{B}_{3}$ & c & {$[0.108,0.989,-0.839,-0.899,-0.545]$} & $\mathrm{B}_{2}-\mathrm{B}_{3}$ & \\
\hline LLG(bc) & $\mathrm{a}$ & {$[-0.559,0.856,0.943,-0.005,0.228]$} & $\mathrm{B}_{2}-\mathrm{B}_{3}$ & \multirow{3}{*}{$\mathrm{B}_{2}-\mathrm{B}_{3}$} \\
\hline $5 \Omega$ & $\mathrm{b}$ & {$[0.649,0.974,-0.701,-0.967,-0.431]$} & $\mathrm{B}_{2}-\mathrm{B}_{3}$ & \\
\hline $\mathrm{B}_{2}-\mathrm{B}_{3}$ & c & {$[0.637,0.973,-0.749,-0.961,0.307]$} & healthy & \\
\hline LLL & a & {$[-0.948,-0.870,-0.585,0.053,-0.319]$} & $\mathrm{B}_{4}-\mathrm{B}_{5}$ & \multirow{3}{*}{$\mathrm{B}_{4}-\mathrm{B}_{5}$} \\
\hline $10 \Omega$ & $\mathrm{b}$ & {$[-0.935,-0.843,-0.515,0.619,-0.302]$} & $\mathrm{B}_{4}-\mathrm{B}_{5}$ & \\
\hline $\mathrm{B}_{4}-\mathrm{B}_{5}$ & c & {$[-0.987,-0.969,-0.193,0.575,-0.515]$} & $\mathrm{B}_{4}-\mathrm{B}_{5}$ & \\
\hline
\end{tabular}

TABLE 7: The feature cosine of each bus and judgment results in unbalanced loads.

\begin{tabular}{|c|c|c|c|c|}
\hline $\begin{array}{l}F_{\mathrm{t}} \\
R_{\mathrm{f}} \\
F_{\mathrm{L}} \\
O_{\mathrm{m}} \\
\end{array}$ & $P$ & {$\left[\mathrm{~B}_{1}, \mathrm{~B}_{2}, \mathrm{~B}_{3}, \mathrm{~B}_{4}, \mathrm{~B}_{5}\right]$} & $\begin{array}{r}\text { Each } P \\
\text { result }\end{array}$ & $\begin{array}{l}\text { Final } \\
\text { result }\end{array}$ \\
\hline LG(a) & a & {$[-0.999,0.999,0.999,0.995,0.997]$} & $\mathrm{B}_{1}-\mathrm{B}_{2}$ & \multirow{3}{*}{$\mathrm{B}_{1}-\mathrm{B}_{2}$} \\
\hline $0.1 \Omega$ & $\mathrm{b}$ & {$[0.653,0.667,0.675,-0.867,-0.851]$} & healthy & \\
\hline $\begin{array}{l}\mathrm{B}_{1}-\mathrm{B}_{2} \\
\text { islanded }\end{array}$ & c & {$[0.840,0.852,0.859,-0.911,-0.902]$} & healthy & \\
\hline$\overline{L L}(\mathrm{ab})$ & $\mathrm{a}$ & {$[-0.969,-0.834,0.948,0.951,0.984]$} & $\mathrm{B}_{2}-\mathrm{B}_{3}$ & \multirow{3}{*}{$\mathrm{B}_{2}-\mathrm{B}_{3}$} \\
\hline $0.1 \Omega$ & $\mathrm{b}$ & {$[-0.718,-0.043,-0.856,0.909,0.931]$} & healthy & \\
\hline $\begin{array}{l}\mathrm{B}_{2}-\mathrm{B}_{3} \\
\text { islanded }\end{array}$ & c & {$[0.948,0.949,0.949,-0.999,-0.998]$} & $\mathrm{B}_{2}-\mathrm{B}_{3}$ & \\
\hline LLLG & a & {$[0.994,0.999,1.000,-0.991,0.985]$} & $\mathrm{B}_{4}-\mathrm{B}_{5}$ & \multirow{3}{*}{$\mathrm{B}_{4}-\mathrm{B}_{5}$} \\
\hline $0.1 \Omega$ & $\mathrm{b}$ & {$[0.936,0.979,0.987,-1.021,1.095]$} & $\mathrm{B}_{4}-\mathrm{B}_{5}$ & \\
\hline $\begin{array}{l}\mathrm{B}_{4}-\mathrm{B}_{5} \\
\text { islanded }\end{array}$ & c & {$[1.095,1.023,1.006,-0.991,0.966]$} & $\mathrm{B}_{4}-\mathrm{B}_{5}$ & \\
\hline $\mathrm{LG}(\mathrm{b})$ & a & {$[-0.167,-0.191,-0.208,0.115,0.109]$} & healthy & \multirow{3}{*}{$\mathrm{B}_{1}-\mathrm{B}_{2}$} \\
\hline $1 \Omega$ & $\mathrm{b}$ & {$[0.999,-0.980,-0.980,-0.137,-0.169]$} & $\mathrm{B}_{1}-\mathrm{B}_{2}$ & \\
\hline $\begin{array}{l}\mathrm{B}_{1}-\mathrm{B}_{2} \\
\text { Grid }\end{array}$ & c & {$[-0.774,-0.780,-0.785,-0.296,-0.298]$} & healthy & \\
\hline LLG(ab) & $\mathrm{a}$ & {$[0.958,0.735,-0.921,-0.456,-0.557]$} & $\mathrm{B}_{2}-\mathrm{B}_{3}$ & \multirow{3}{*}{$\mathrm{B}_{2}-\mathrm{B}_{3}$} \\
\hline $1 \Omega$ & $\mathrm{b}$ & {$[0.837,0.341,0.798,-0.993,-0.997]$} & healthy & \\
\hline $\begin{array}{l}\text { Grid } \\
\mathrm{B}_{2}-\mathrm{B}_{3} \\
\end{array}$ & c & {$[-0.960,-0.961,-0.962,0.588,0.582]$} & healthy & \\
\hline LLLG & $\mathrm{a}$ & {$[-0.836,-0.880,-0.899,0.997,-0.994]$} & $\mathrm{B}_{4}-\mathrm{B}_{5}$ & \multirow{3}{*}{$\mathrm{B}_{4}-\mathrm{B}_{5}$} \\
\hline $1 \Omega$ & $\mathrm{b}$ & {$[-0.840,-0.887,-0.912,0.993,-1.038]$} & $\mathrm{B}_{4}-\mathrm{B}_{5}$ & \\
\hline $\begin{array}{l}\text { Grid } \\
\mathrm{B}_{4}-\mathrm{B}_{5}\end{array}$ & c & {$[-0.933,-0.952,-0.964,0.994,-0.899]$} & $\mathrm{B}_{4}-\mathrm{B}_{5}$ & \\
\hline
\end{tabular}




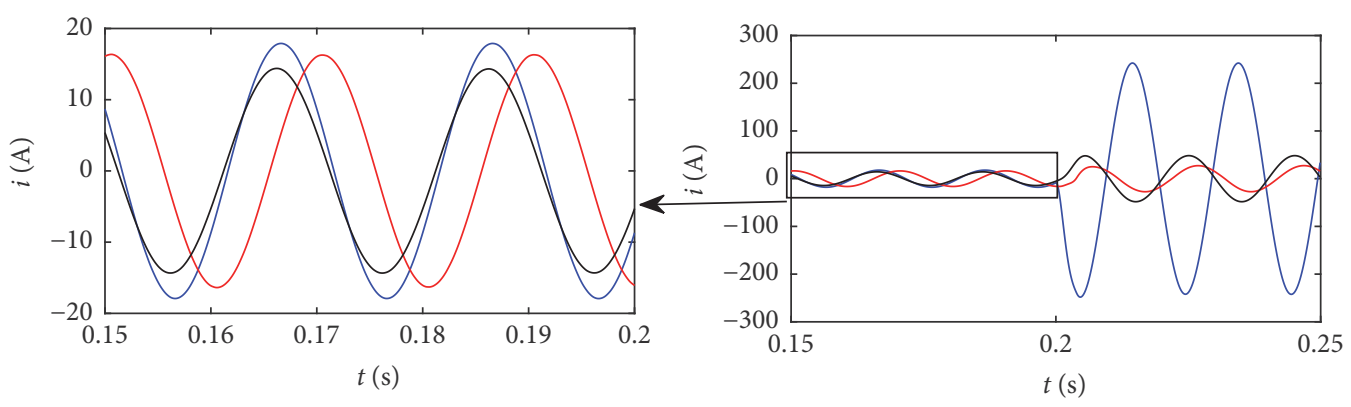

(a)
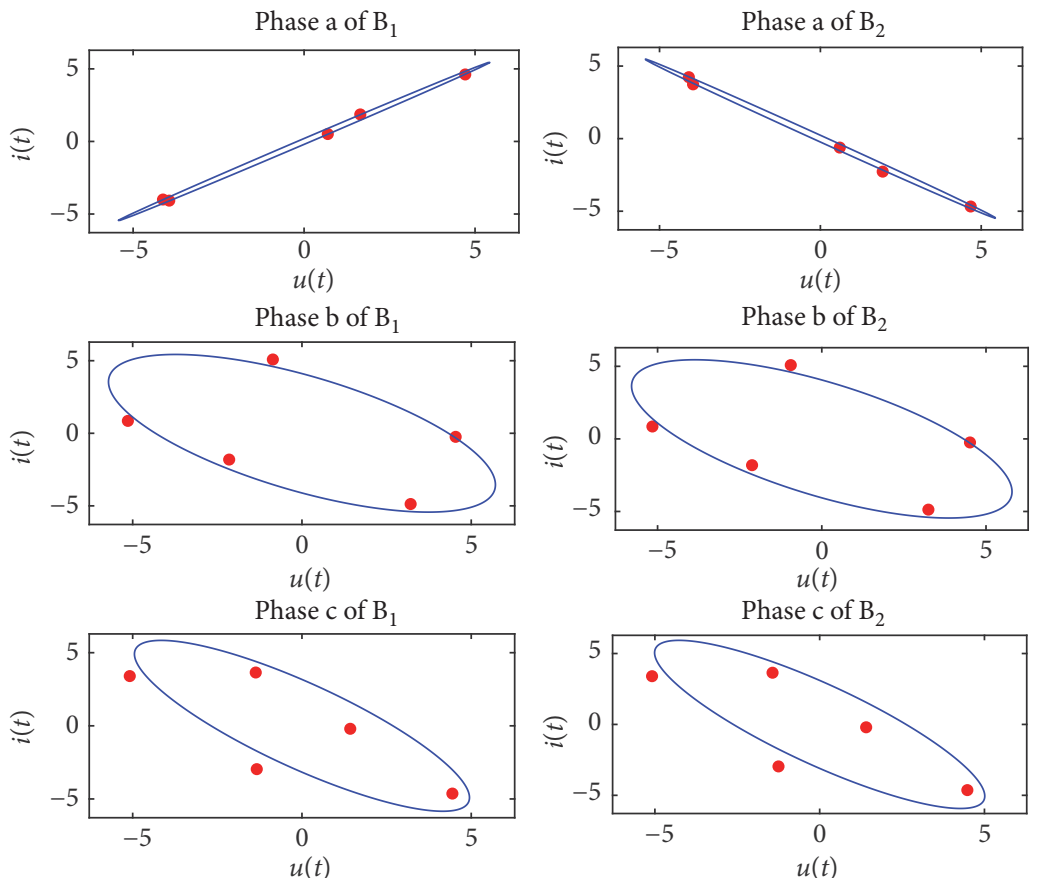

- $\quad$ Sampling points

Fitting curve

(b)

Figure 9: The $\mathrm{B}_{2}$ current and bus ellipse for $\mathrm{B}_{1}$ and $\mathrm{B}_{2}$; (a) $\mathrm{B}_{2}$ current, (b) bus ellipse of three phases.

achieve the faulty section location detection in different faulty conditions for the microgrid whose nodes are with only loads.

\section{Discussion}

When different faults, including different faulty resistances and faulty section, occur in microgrid at $0.2 \mathrm{~s}$, Figure 12 shows the fault current peak value of $B_{1}$ whose time length is from $0.21 \mathrm{~s} \sim 0.23 \mathrm{~s}$.

It is shown in Figure 10 that the $B_{1}$ fault current in grid connected mode is higher compared with the islanded mode; besides, the $B_{1}$ fault current decreases for the faults occurring on the lines away from the $\mathrm{B}_{1}$. So, as for fault current, there is a difference between grid connected and islanded modes; besides, if the microgrid has unbalanced loads, its fault current for each phase is obviously different. It can be concluded that most commercially used overcurrent relay with a preset threshold to operate in grid connected mode may fail or may take a longer time to operate in islanded mode [2]. Hence, [14] has different thresholds to detect fault when the microgrid is operated in different modes. However, [14] did not consider the condition of unbalanced load and will make the protection scheme more complex. Hence, in this paper, the protection method, which has the same threshold in different operation mode and unbalanced load, is proposed and superior to [14].

\section{Conclusion}

Based on the geometric representation of one phase in a bus and the analysis of feature cosine of different buses, this paper proposes a protection method to detect the faulty section location using the differential direction. The proposed method uses comprehensively every phase voltage 


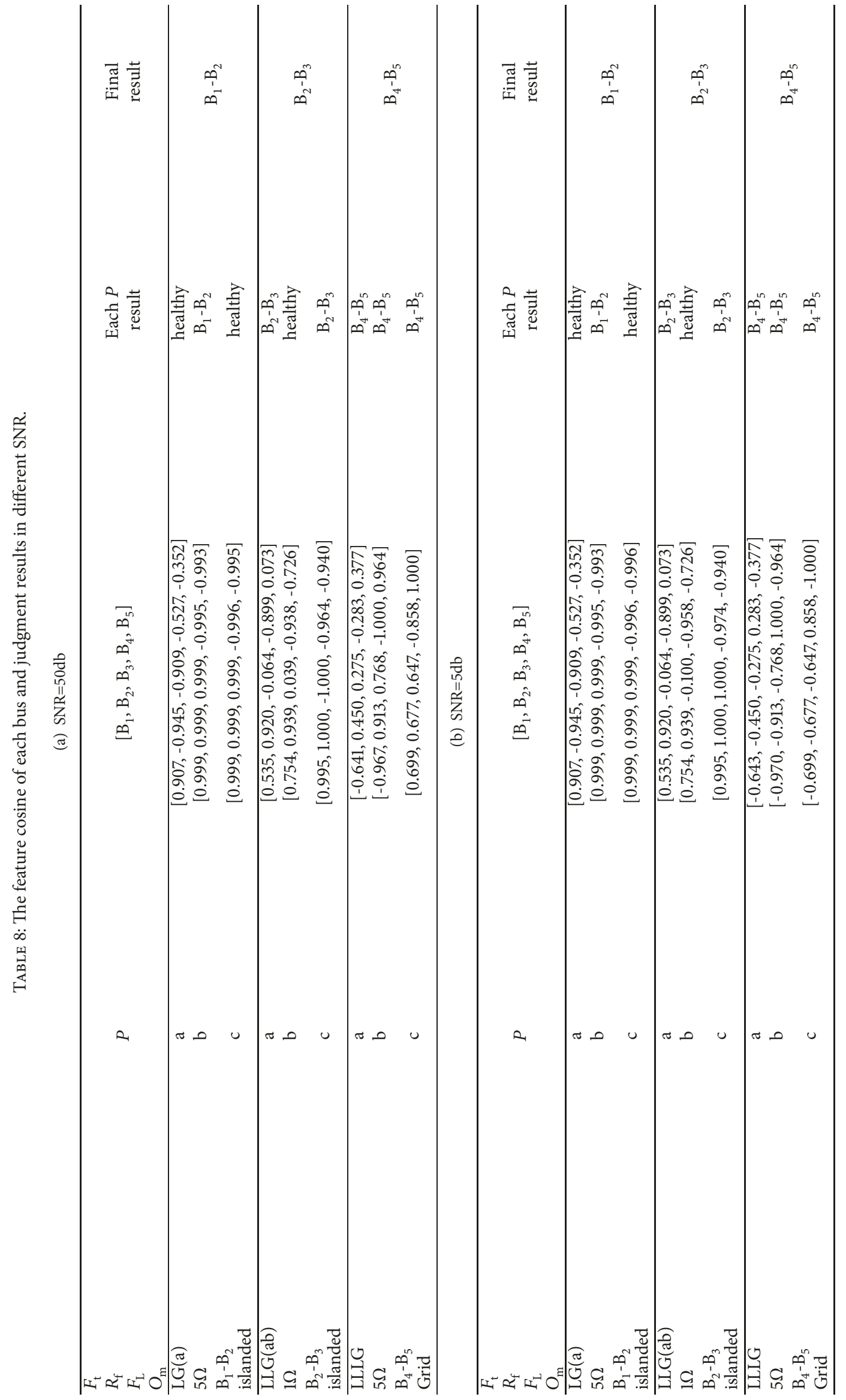




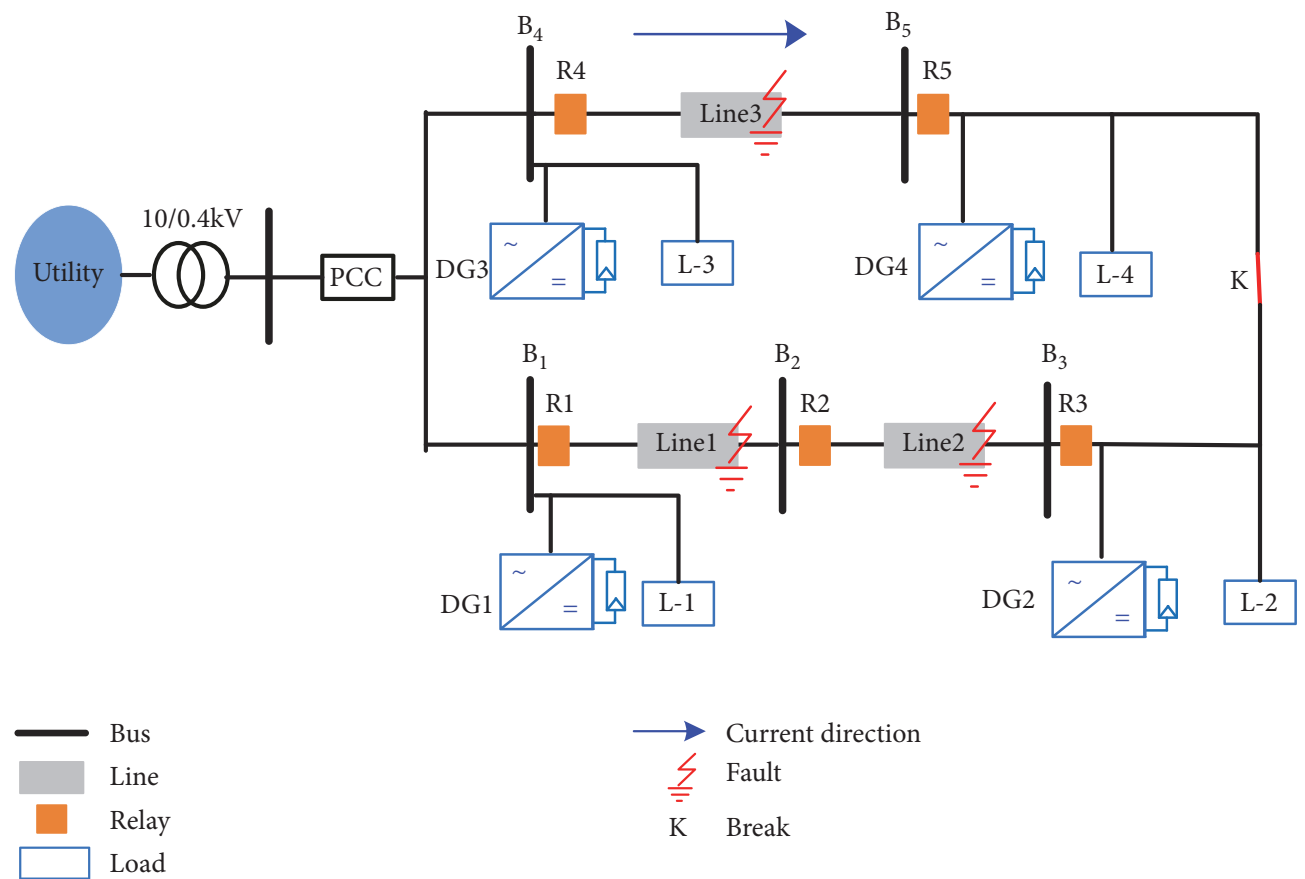

FIGURE 10: The looped microgrid.

TABLE 9: The feature cosine of each bus and judgment results for the looped microgrid.

\begin{tabular}{|c|c|c|c|c|}
\hline $\begin{array}{l}F_{\mathrm{t}} \\
R_{\mathrm{f}} \\
F_{\mathrm{L}} \\
O_{\mathrm{m}}\end{array}$ & $P$ & {$\left[\mathrm{~B}_{1}, \mathrm{~B}_{2}, \mathrm{~B}_{3}, \mathrm{~B}_{4}, \mathrm{~B}_{5}\right]$} & $\begin{array}{r}\text { Each } P \\
\text { result }\end{array}$ & $\begin{array}{l}\text { Final } \\
\text { result }\end{array}$ \\
\hline LG(a) & a & {$[0.965,-0.973,-0.949,-0.790,-0.741]$} & $\mathrm{B}_{1}-\mathrm{B}_{2}$ & \multirow{3}{*}{$\mathrm{B}_{1}-\mathrm{B}_{2}$} \\
\hline $0.1 \Omega$ & $\mathrm{b}$ & {$[-1.102,-1.103,-1.103,-1.098,-1.100]$} & healthy & \\
\hline $\begin{array}{l}\mathrm{B}_{1}-\mathrm{B}_{2} \\
\text { islanded }\end{array}$ & c & {$[-1.043,-1.044,-1.044,-1.040,-1.041]$} & healthy & \\
\hline LLG(ab) & a & {$[0.932,0.978,-0.929,0.958,0.980]$} & $\mathrm{B}_{2}-\mathrm{B}_{3}$ & \multirow{3}{*}{$\mathrm{B}_{2}-\mathrm{B}_{3}$} \\
\hline $0.1 \Omega$ & $\mathrm{b}$ & {$[0.535,0.763,-0.500,0.657,0.788]$} & $\mathrm{B}_{2}-\mathrm{B}_{3}$ & \\
\hline $\begin{array}{l}\mathrm{B}_{2}-\mathrm{B}_{3} \\
\text { islanded }\end{array}$ & c & {$[0.997,0.998,0.998,0.997,0.998]$} & healthy & \\
\hline LLLG & a & {$[-0.906,-0.896,-0.887,0.691,-0.673]$} & $\mathrm{B}_{4}-\mathrm{B}_{5}$ & \multirow{3}{*}{$\mathrm{B}_{4}-\mathrm{B}_{5}$} \\
\hline $0.1 \Omega$ & $\mathrm{b}$ & {$[-0.654,-0.612,-0.583,0.561,-0.480]$} & $\mathrm{B}_{4}-\mathrm{B}_{5}$ & \\
\hline $\begin{array}{l}\mathrm{B}_{4}-\mathrm{B}_{5} \\
\text { islanded }\end{array}$ & c & {$[-1.032,-1.032,-1.031,0.918,-0.932]$} & $\mathrm{B}_{4}-\mathrm{B}_{5}$ & \\
\hline LG(b) & a & {$[0.534,-0.953,-0.912,0.386,0.939]$} & $\mathrm{B}_{1}-\mathrm{B}_{2}$ & \multirow{3}{*}{$\mathrm{B}_{1}-\mathrm{B}_{2}$} \\
\hline $1 \Omega$ & $\mathrm{b}$ & {$[1.275,0.767,0.933,1.273,0.933]$} & healthy & \\
\hline $\begin{array}{l}\mathrm{B}_{1}-\mathrm{B}_{2} \\
\text { Grid }\end{array}$ & c & {$[0.647,0.764,0.928,0.645,0.928]$} & healthy & \\
\hline LLG(ac) & a & {$[0.393,0.935,-0.788,0.673,0.938]$} & $\mathrm{B}_{2}-\mathrm{B}_{3}$ & \multirow{3}{*}{$\mathrm{B}_{2}-\mathrm{B}_{3}$} \\
\hline $1 \Omega$ & $\mathrm{b}$ & {$[-0.357,0.880,1.007,-0.357,1.006]$} & healthy & \\
\hline $\begin{array}{l}\text { Grid } \\
\mathrm{B}_{2}-\mathrm{B}_{3}\end{array}$ & c & {$[0.357,0.953,-0.856,0.724,0.937]$} & $\mathrm{B}_{2}-\mathrm{B}_{3}$ & \\
\hline LLLG & $\mathrm{a}$ & {$[0.551,0.746,0.819,0.531,-0.831]$} & $\mathrm{B}_{4}-\mathrm{B}_{5}$ & \multirow{3}{*}{$\mathrm{B}_{4}-\mathrm{B}_{5}$} \\
\hline $1 \Omega$ & $\mathrm{b}$ & {$[0.442,0.588,0.662,0.292,-0.503]$} & $\mathrm{B}_{4}-\mathrm{B}_{5}$ & \\
\hline $\begin{array}{l}\text { Grid } \\
\mathrm{B}_{4}-\mathrm{B}_{5}\end{array}$ & c & {$[0.907,1.039,1.067,1.006,-1.051]$} & $\mathrm{B}_{4}-\mathrm{B}_{5}$ & \\
\hline
\end{tabular}


TABLE 10: The feature cosine of each bus and judgment results for the sample microgrid.

\begin{tabular}{|c|c|c|c|c|}
\hline $\begin{array}{l}F_{\mathrm{t}} \\
R_{\mathrm{f}} \\
F_{\mathrm{L}} \\
O_{\mathrm{m}}\end{array}$ & $P$ & {$\left[\mathrm{~B}_{1}, \mathrm{~B}_{2}, \mathrm{~B}_{3}, \mathrm{~B}_{4}, \mathrm{~B}_{5}\right]$} & $\begin{array}{r}\text { Each } P \\
\text { result }\end{array}$ & $\begin{array}{l}\text { Final } \\
\text { result }\end{array}$ \\
\hline LG(a) & a & {$[0.762,-0.981,-0.980,-0.976,-0.973]$} & $\mathrm{B}_{1}-\mathrm{B}_{2}$ & \multirow{3}{*}{$\mathrm{B}_{1}-\mathrm{B}_{2}$} \\
\hline $0.3 \Omega$ & $\mathrm{b}$ & {$[-0.988,-0.987,-0.987,-0.981,-0.973]$} & healthy & \\
\hline $\begin{array}{l}\mathrm{B}_{1}-\mathrm{B}_{2} \\
\text { islanded }\end{array}$ & c & {$[-0.987,-0.987,-0.987,-0.981,-0.971]$} & healthy & \\
\hline LLG(ab) & a & {$[1.087,1.006,-0.973,-0.990,-0.988]$} & $\mathrm{B}_{2}-\mathrm{B}_{3}$ & \multirow{3}{*}{$\mathrm{B}_{2}-\mathrm{B}_{3}$} \\
\hline $0.3 \Omega$ & $\mathrm{b}$ & {$[0.310,0.689,-0.969,-0.950,-0.944]$} & $\mathrm{B}_{2}-\mathrm{B}_{3}$ & \\
\hline $\begin{array}{l}\mathrm{B}_{2}-\mathrm{B}_{3} \\
\text { islanded }\end{array}$ & c & {$[-0.984,-0.984,-0.983,-0.976,-0.974]$} & healthy & \\
\hline LLL & a & {$[-0.978,-0.977,-0.977,0.427,-0.965]$} & $\mathrm{B}_{4}-\mathrm{B}_{5}$ & \multirow{3}{*}{$\mathrm{B}_{4}-\mathrm{B}_{5}$} \\
\hline / & $\mathrm{b}$ & {$[-0.973,-0.972,-0.971,0.291,-0.956]$} & $\mathrm{B}_{4}-\mathrm{B}_{5}$ & \\
\hline $\begin{array}{l}\mathrm{B}_{4}-\mathrm{B}_{5} \\
\text { islanded }\end{array}$ & c & {$[-0.971,-0.970,-0.970,0.420,-0.956]$} & $\mathrm{B}_{4}-\mathrm{B}_{5}$ & \\
\hline LG(b) & a & {$[-0.990,-0.990,-0.989,-0.981,-0.978]$} & healthy & \multirow{3}{*}{$\mathrm{B}_{1}-\mathrm{B}_{2}$} \\
\hline $3 \Omega$ & $\mathrm{b}$ & {$[0.071,-1.027,-1.027,-1.152,-1.159]$} & $\mathrm{B}_{1}-\mathrm{B}_{2}$ & \\
\hline $\begin{array}{l}B_{1}-B_{2} \\
\text { Grid }\end{array}$ & c & {$[-0.989,-0.989,-0.989,-0.981,-0.978]$} & healthy & \\
\hline LLG(ac) & a & {$[0.435,0.966,-0.979,-0.949,-0.946]$} & $\mathrm{B}_{2}-\mathrm{B}_{3}$ & \multirow{3}{*}{$\mathrm{B}_{2}-\mathrm{B}_{3}$} \\
\hline $3 \Omega$ & $\mathrm{b}$ & {$[-0.976,-0.976,-0.976,-0.965,-0.961]$} & healthy & \\
\hline $\begin{array}{l}\text { Grid } \\
\mathrm{B}_{2}-\mathrm{B}_{3} \\
\end{array}$ & c & {$[0.563,0.967,-0.979,-0.952,-0.945]$} & $\mathrm{B}_{2}-\mathrm{B}_{3}$ & \\
\hline LLLG & a & {$[-0.977,-0.976,-0.976,0.283,-0.965]$} & $\mathrm{B}_{4}-\mathrm{B}_{5}$ & \multirow{3}{*}{$\mathrm{B}_{4}-\mathrm{B}_{5}$} \\
\hline $3 \Omega$ & $\mathrm{b}$ & {$[-0.965,-0.964,-0.963,0.246,-0.956]$} & $\mathrm{B}_{4}-\mathrm{B}_{5}$ & \\
\hline $\begin{array}{l}\text { Grid } \\
\mathrm{B}_{4}-\mathrm{B}_{5}\end{array}$ & c & {$[-0.962,-0.962,-0.961,0.447,-0.956]$} & $\mathrm{B}_{4}-\mathrm{B}_{5}$ & \\
\hline
\end{tabular}

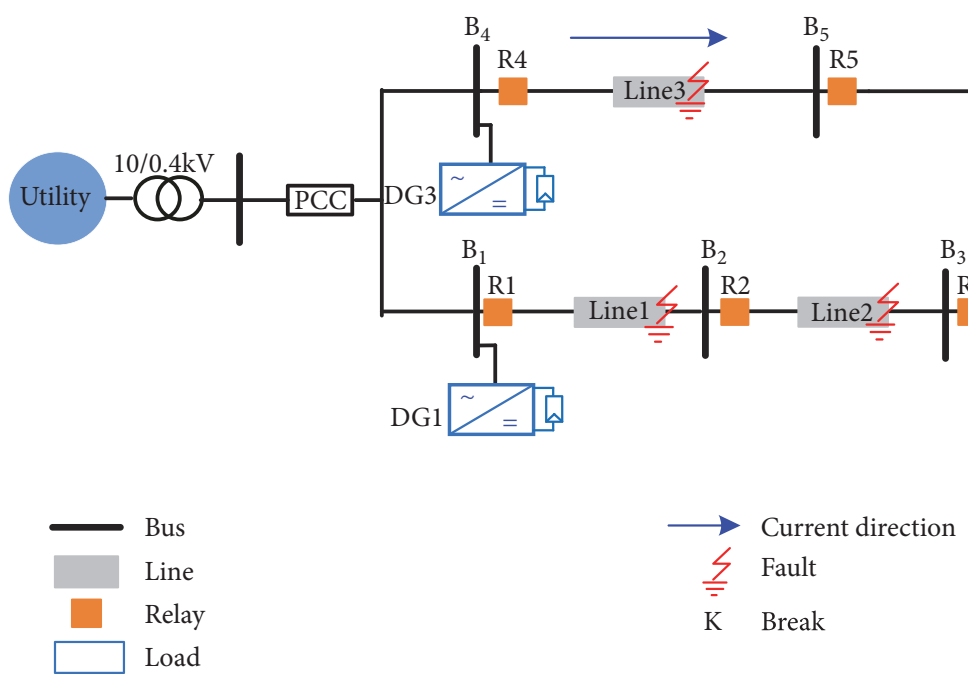

FIGURE 11: Sample microgrid whose nodes are with only loads. 


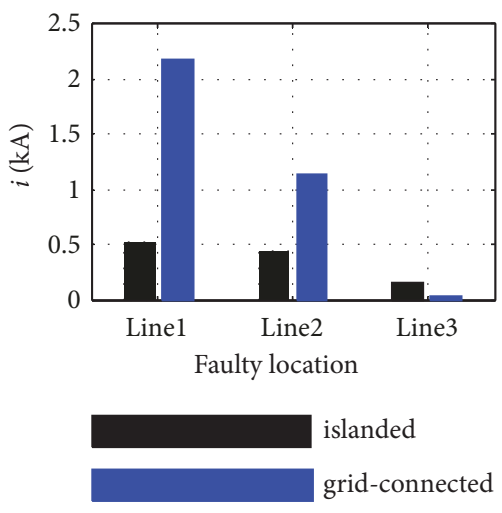

(a)

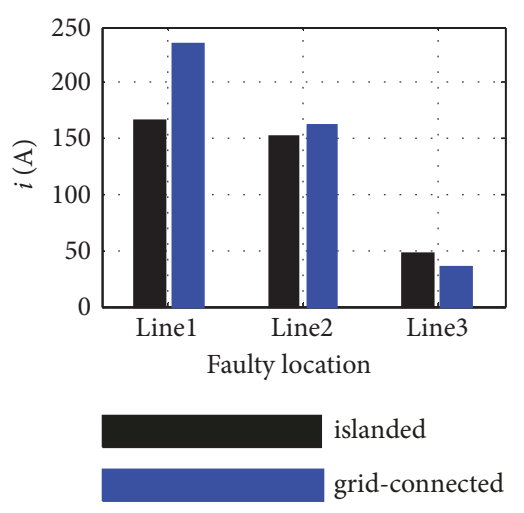

(b)

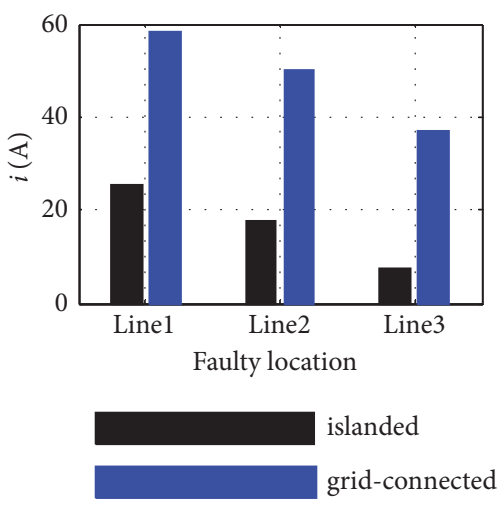

(c)

Figure 12: Fault current peak value of $\mathrm{B}_{1}$ in different $R_{\mathrm{f}}$. (a) $0.01 \Omega$; (b) $1 \Omega$; (c) $10 \Omega$.

and current to calculate the differential direction; this method is found to work effectively under various case studies as discussed in this paper including different grounding resistances and faulty types. The advantage of the proposed method is that it is not needed to change the threshold to detect the faulty section location when the microgrid operation mode is changed and has unbalanced loads.

\section{Data Availability}

The data used to support the findings of this study are available from the corresponding author upon request.

\section{Conflicts of Interest}

The authors declare that there are no conflicts of interest regarding the publication of this article.

\section{Acknowledgments}

This work is supported by University-Level Scientific Research Project (ZEPCKY2019-01) of Zhengzhou Electric Power College, China.

\section{References}

[1] H. Xiao, A. Luo, Z. Shuai, G. Jin, and Y. Huang, "An improved control method for multiple bidirectional power converters in hybrid AC/DC microgrid," IEEE Transactions on Smart Grid, vol. 7, no. 1, pp. 340-347, 2016.

[2] X. Wang, J. Gao, X. Wei et al., "High impedance fault detection method based on variational mode decomposition and TeagerKaiser energy operators for distribution network," IEEE Transactions on Smart Grid, Early Access, p. 1, 2019.

[3] X. Wang, J. Gao, M. Chen, X. Wei, Y. Wei, and Z. Zeng, "Faulty line detection method based on optimized bistable system for distribution network," IEEE Transactions on Industrial Informatics, vol. 14, no. 4, pp. 1370-1381, 2018.

[4] A. Hooshyar and R. Iravani, "Microgrid protection," Proceedings of the IEEE, vol. 105, no. 7, pp. 1332-1353, 2017.
[5] X. Liu, M. Shahidehpour, Z. Li, X. Liu, Y. Cao, and W. Tian, "Protection scheme for loop-based microgrids," IEEE Transactions on Smart Grid, vol. 8, no. 3, pp. 1340-1349, 2017.

[6] S. Teimourzadeh, F. Aminifar, M. Davarpanah, and M. Shahidehpour, "Adaptive protection for preserving microgrid security," IEEE Transactions on Smart Grid, vol. 10, no. 1, pp. 592-600, 2019.

[7] Z. Chen, X. Pei, M. Yang, L. Peng, and P. Shi, "A novel protection scheme for inverter-interfaced microgrid (IIM) operated in islanded mode," IEEE Transactions on Power Electronics, vol. 33, no. 9, pp. 7684-7697, 2018.

[8] H. J. Laaksonen, "Protection principles for future microgrids," IEEE Transactions on Power Electronics, vol. 25, no. 12, pp. 29102918, 2010.

[9] H. Muda and P. Jena, "Superimposed adaptive sequence current based microgrid protection: a new technique," IEEE Transactions on Power Delivery, vol. 32, no. 2, pp. 757-767, 2017.

[10] S. Mirsaeidi, D. M. Said, M. W. Mustafa, and M. H. Habibuddin, "A protection strategy for micro-grids based on positivesequence component," IET Renewable Power Generation, vol. 9, no. 6, pp. 600-609, 2015.

[11] J. Duan, K. Zhang, and L. Cheng, "A novel method of fault location for single-phase microgrids," IEEE Transactions on Smart Grid, vol. 7, no. 2, pp. 915-925, 2016.

[12] S. A. Saleh, R. Ahshan, M. S. Abu-Khaizaran, B. Alsayid, and M. A. Rahman, "Implementing and testing d-q WPT-based digital protection for microgrid systems," IEEE Transactions on Industry Applications, vol. 50, no. 3, pp. 2173-2185, 2014.

[13] A. Gururani, S. R. Mohanty, and J. C. Mohanta, "Microgrid protection using Hilbert-Huang transform based-differential scheme," IET Generation, Transmission \& Distribution, vol. 10, no. 15, pp. 3707-3716, 2016.

[14] S. Kar and S. R. Samantaray, "Time-frequency transform-based differential scheme for microgrid protection," IET Generation, Transmission \& Distribution, vol. 8, no. 2, pp. 310-320, 2014.

[15] E. Casagrande, W. L. Woon, H. H. Zeineldin, and N. H. Kan'an, "Data mining approach to fault detection for isolated inverter-based microgrids," IET Generation, Transmission \& Distribution, vol. 7, no. 7, pp. 745-754, 2013.

[16] E. Casagrande, W. L. Woon, H. H. Zeineldin, and D. Svetinovic, "A differential sequence component protection scheme for microgrids with inverter-based distributed generators," IEEE Transactions on Smart Grid, vol. 5, no. 1, pp. 29-37, 2014. 
[17] D. P. Mishra, S. R. Samantaray, and G. Joos, "A combined wavelet and data-mining based intelligent protection scheme for microgrid," IEEE Transactions on Smart Grid, vol. 7, no. 5, pp. 2295-2304, 2016.

[18] S. Kar, S. R. Samantaray, and M. D. Zadeh, "Data-mining model based intelligent differential microgrid protection scheme," IEEE Systems Journal, vol. 11, no. 2, pp. 1161-1169, 2017.

[19] A. De Souza Gomes, M. A. Costa, T. G. A. Defaria, and W. M. Caminhas, "Detection and classification of faults in power transmission lines using functional analysis and computational intelligence," IEEE Transactions on Power Delivery, vol. 28, no. 3, pp. 1402-1413, 2013.

[20] C. Ma and L. Jiang, "Some research on Levenberg-Marquardt method for the nonlinear equations," Applied Mathematics and Computation, vol. 184, no. 2, pp. 1032-1040, 2007.

[21] P. Piagi and R. H. Lasseter, "Autonomous control of microgrids," in Proceedings of the 2006 IEEE Power Engineering Society General Meeting, PES, Canada, June 2006.

[22] K. Yu, Q. Ai, S. Wang, J. Ni, and T. Lv, "Analysis and optimization of droop controller for microgrid system based on small-signal dynamic model," IEEE Transactions on Smart Grid, vol. 7, no. 2, pp. 695-705, 2016.

[23] M. Yazdanian and A. Mehrizi-Sani, "Washout filter-based power sharing," IEEE Transactions on Smart Grid, vol. 7, no. 2, pp. 967-968, 2016.

[24] K. O. Oureilidis and C. S. Demoulias, "A fault clearing method in converter-dominated microgrids with conventional protection means," IEEE Transactions on Power Electronics, vol. 31, no. 6, pp. 4628-4640, 2016.

[25] B. Dag, A. R. Boynuegri, Y. Ates, A. Karakas, A. Nadar, and M. Uzunoglu, "Static modeling of microgrids for load flow and fault analysis," IEEE Transactions on Power Systems, vol. 32, no. 3, pp. 1990-2000, 2017.

[26] B. Jiang, L. Mu, W. Guo, and W. Zhuang, "Microgrid protection based on change of measured bus admittance," Power System Technology, vol. 39, no. 6, pp. 1751-1758, 2015.

[27] H. Zhang, T. R. Blackburn, B. T. Phung, and D. Sen, "A novel wavelet transform technique for on-line partial discharge measurements part 1: WT de-noising algorithm," IEEE Transactions on Dielectrics and Electrical Insulation, vol. 14, no. 1, pp. 3-14, 2007. 


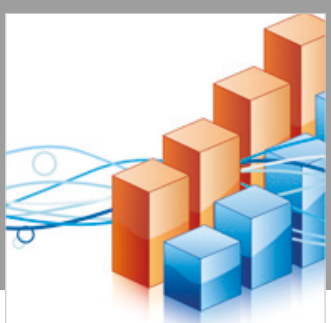

Advances in

Operations Research

\section{-n-m}
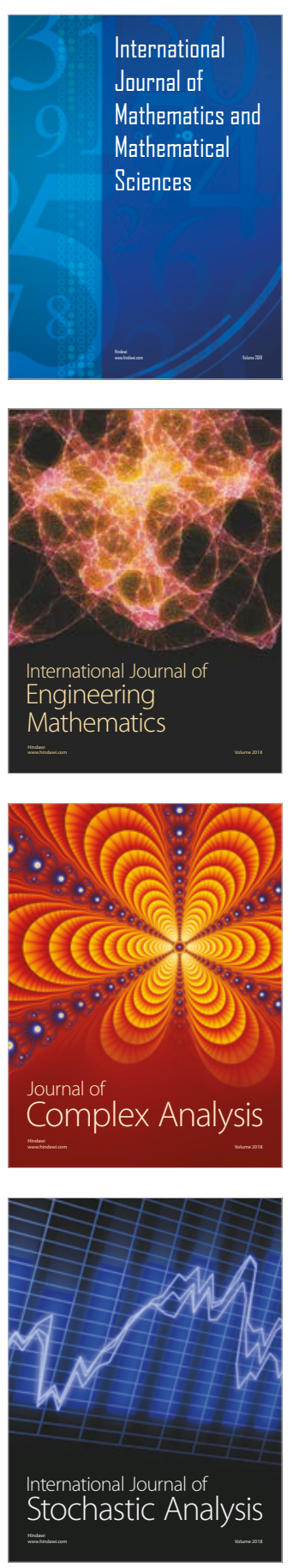
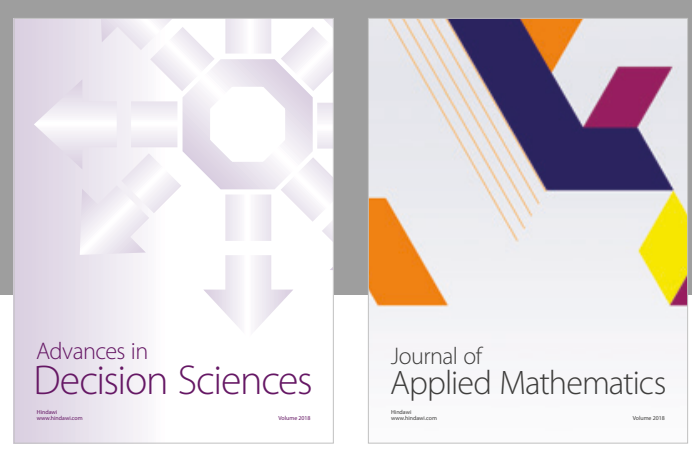

Journal of

Applied Mathematics
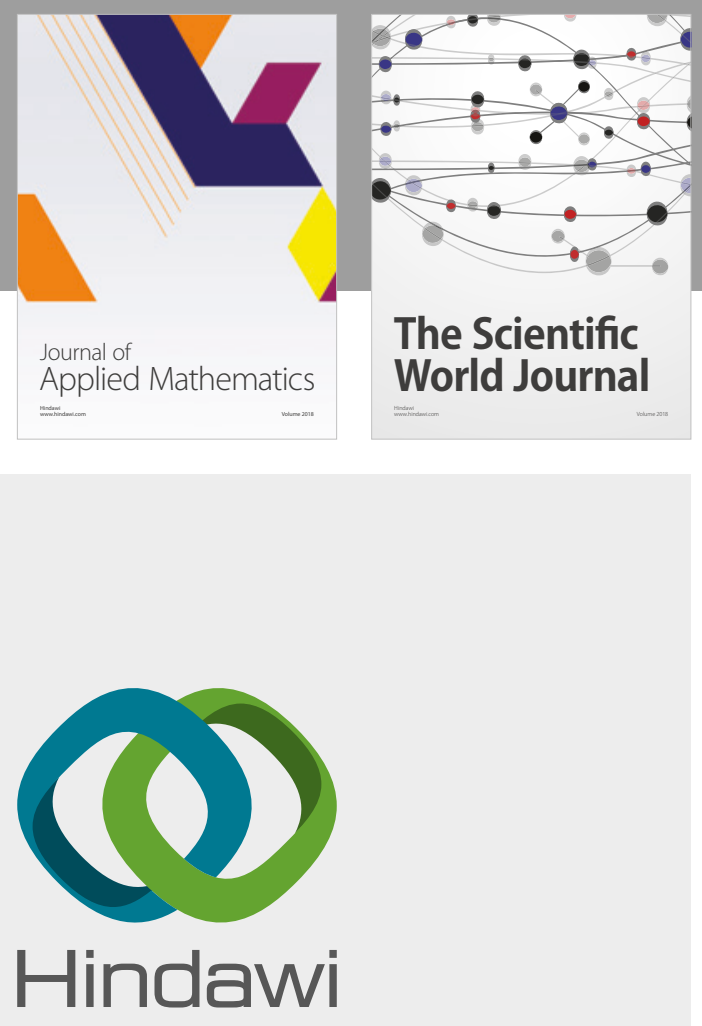

Submit your manuscripts at

www.hindawi.com

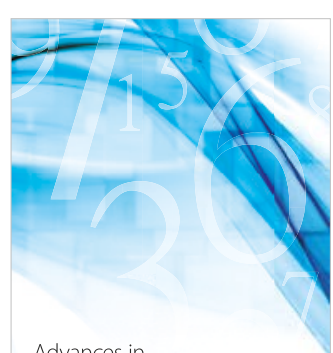

Advances in
Numerical Analysis
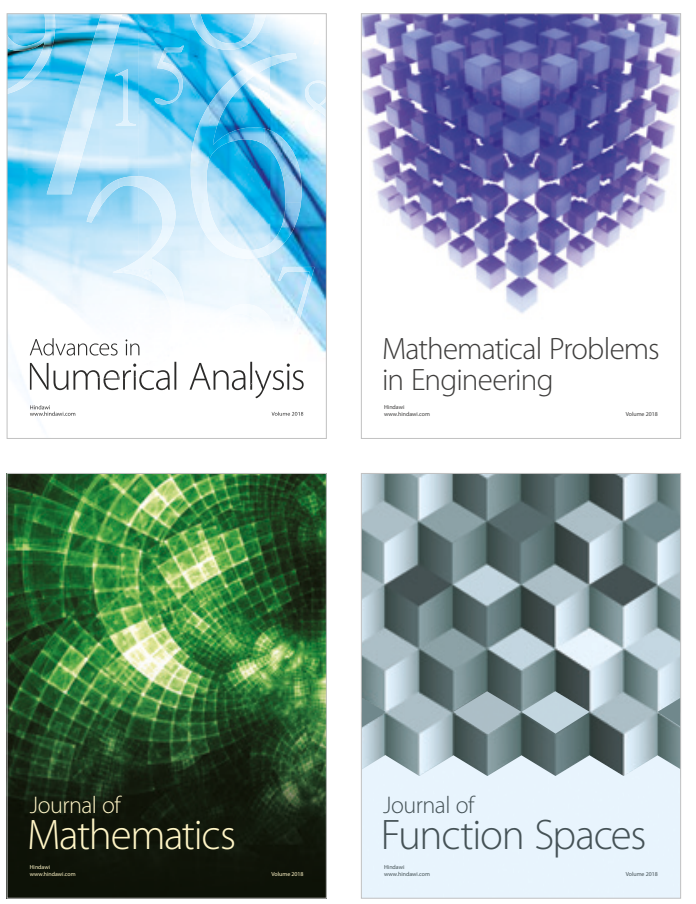

Mathematical Problems in Engineering

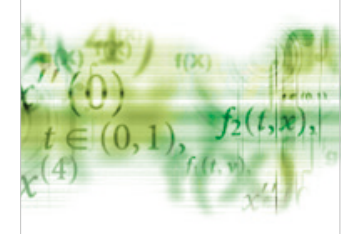

International Journal of

Differential Equations

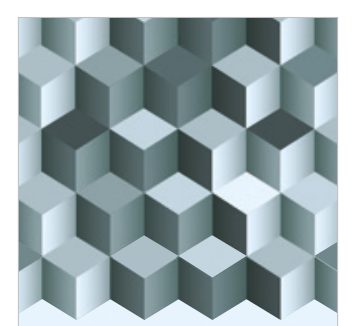

Journal of

Function Spaces

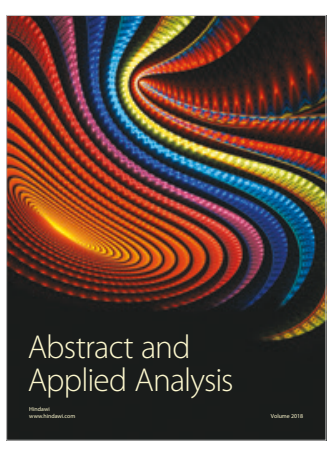

The Scientific

World Journal

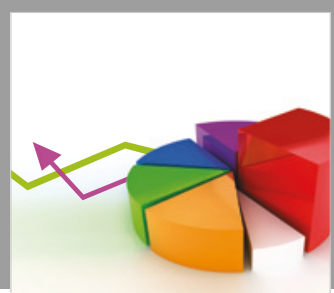

Journal of

Probability and Statistics
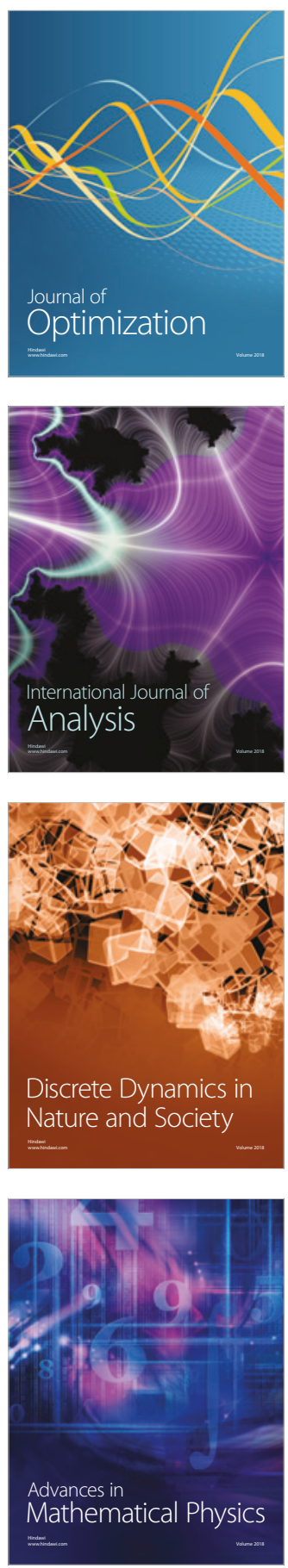